\title{
Palladium-Catalyzed Suzuki-Miyaura Cross-Coupling in Continuous Flow
}

\author{
Christophe Len ${ }^{1, *}$, Sophie Bruniaux ${ }^{1}$, Frederic Delbecq ${ }^{2}$ and Virinder S. Parmar ${ }^{3}$ \\ 1 Centre de Recherche Royallieu, Université de Technologie de Compiègne (UTC), Sorbonne Universités, \\ CS 60319, F-60203 Compiègne CEDEX, France; sophie.bruniaux@utc.fr \\ 2 Ecole Supérieure de Chimie Organique et Minérale (ESCOM), 1 rue du Réseau Jean-Marie Buckmaster, \\ F-60200 Compiègne, France; f.delbecq@escom.fr \\ 3 Institute of Advanced Sciences, 86-410 Faunce Corner Mall Road, Dartmouth, MA 02747, USA; \\ virparmar@gmail.com \\ * Correspondence: christophe.len@utc.fr; Tel.: +33-344-234-323
}

Academic Editor: Ioannis D. Kostas

Received: 15 March 2017; Accepted: 25 April 2017; Published: 9 May 2017

\begin{abstract}
Carbon-carbon cross-coupling reactions are among the most important processes in organic chemistry and Suzuki-Miyaura reactions are the most widely used protocols. For a decade, green chemistry and particularly catalysis and continuous flow, have shown immense potential in achieving the goals of "greener synthesis". To date, it seems difficult to conceive the chemistry of the 21st century without the industrialization of continuous flow process in the area of pharmaceuticals, drugs, agrochemicals, polymers, etc. A large variety of palladium Suzuki-Miyaura cross-coupling reactions have been developed using a continuous flow sequence for preparing the desired biaryl derivatives. Our objective is to focus this review on the continuous flow Suzuki-Miyaura cross-coupling using homogeneous and heterogeneous catalysts.
\end{abstract}

Keywords: palladium; continuous flow; Suzuki-Miyaura; cross-coupling

\section{Introduction}

Among the main reactions in organic chemistry, $\mathrm{C}-\mathrm{C}$ bond formation via a cross-coupling reaction catalyzed by transition metals is undoubtedly the most important and has been exploited very widely in the recent years. Palladium, the most widely used metal, enables the synthesis of complex and functionalized organic molecules and its chemistry possesses different interesting facets such as heterogeneous and homogeneous catalysis under mild experimental conditions compatible with many functional groups [1-5]. Several palladium catalyzed cross-coupling reactions such as Heck [6-11], Suzuki [12-16], Sonogashira [17-21], Stille [22-25], Hiyama [26], Negishi [27], Kumada [28], Murahashi [29] and Buchwald-Hartwig [30,31] have been developed over the years.

Due to current impetus in promoting green chemistry for sustainable development, both for academic and industrial research, chemists have recently established catalytic reactions based on renewable resources, atom economy, less hazardous chemical steps, safer (least toxic) solvents, auxiliaries and alternative technologies such as continuous flow, microwave irradiation, ultrasound irradiation, etc. In the context of green chemistry, catalysis and alternative media, different cross-coupling reactions such as Suzuki-Miyaura in batch reactors have been developed in aqueous media or in water as sole green safer solvent via conventional heating or microwave irradiation [32-43]. Continuous flow chemistry as alternative technology offers significant processing advantages including improved thermal management, mixing control, application to a wider range of reaction conditions, scalability, energy efficiency, waste reduction, safety, use of heterogeneous catalysis, multistep synthesis and much more [44-49]. Two different reactors, micro and meso (or flow) reactors, exist and the devices depend on the channel 
dimensions, from 10 to $300 \mu \mathrm{m}$ for the micro reactor (also called milli or mini) and from $300 \mu \mathrm{m}$ to more than $5 \mathrm{~mm}$ for the meso reactor. Several advantages and disadvantages are associated with the micro and meso reactors. The main advantages for the micro reactor are the low material input, low waste output, excellent mass transfer properties, fast diffusive mixing and the disadvantages are the low throughput, tendency to channel blockage and high pressure drop. In the case of solid handling due to confined conditions and increasing of the concentration to have a better productivity, the use of continuous sonication could prevent clogging [50]. For the meso reactor, the advantages are the high throughput, low pressure drop and possibility to handle solids for heterogeneous catalysis. Few disadvantages for meso reactors are poor mass transfer property, slower mixing, etc. Different studies have described the theory and practicalities of scaled-out micro and meso reactors but no practical examples of large-scale production have been described. Palladium-catalyzed cross-coupling reactions in continuous flow reactors have been reported in the literature at temperatures higher than $60^{\circ} \mathrm{C}$ [51-63], while only few studies have described micro and meso reactors for the $\mathrm{C}-\mathrm{C}$ bond formation at temperature lower than $60{ }^{\circ} \mathrm{C}$. In parallel with the synthesis of low molecular weight compounds, this technique has been applied by academic and industrial groups for the production of polymers [64-67]. For the sake of clarity, this review describes continuous flow selective palladium-catalyzed cross-coupling reactions having a good energy efficiency at temperatures ranging between $0{ }^{\circ} \mathrm{C}$ and $80^{\circ} \mathrm{C}$.

\section{Accepted Mechanism of Suzuki Cross-Coupling}

The Suzuki-Miyaura cross-coupling reaction [12-16] is one of the most versatile and frequently employed method for $\mathrm{C}-\mathrm{C}$ bond formation. It consists of the coupling of organoboron compounds (organoborane, organoboronic acid, organoboronate ester and potassium trifluoroborate) with aryl, alkenyl and alkynyl halides. Nowadays, a large variety of boronic acids are commercially available. The general Suzuki-Miyaura catalytic cycle occurs through oxidative addition, transmetallation and reductive elimination [13-15,68-70]. After formation of the catalytic species $\mathrm{Pd}(0)$, generated in situ starting from palladium $\mathrm{Pd}(\mathrm{II})$ or directly from $\mathrm{Pd}(0)$ derivatives, oxidative addition of the aryl halide ArX furnishes the palladium complex (ArPdXLn). The transmetallation step occurs by conversion of the palladium halide ( $\mathrm{ArPdXLn}$ ) in the presence of the base $\mathrm{RO}^{-}$to a nucleophilic palladium alkoxy complex (ArPdORLn). This complex subsequently reacts with a neutral organoboron compound $\mathrm{Ar}^{\prime} \mathrm{B}(\mathrm{OH})_{2}$ to afford the diaryl complex (ArPdAr'Ln) in a cis-trans equilibrium. Then, reductive elimination of the cis form gives the biaryl derivative $\mathrm{Ar}-\mathrm{Ar}^{\prime}$ and $\mathrm{Pd}(0)$ (Scheme 1) [15].

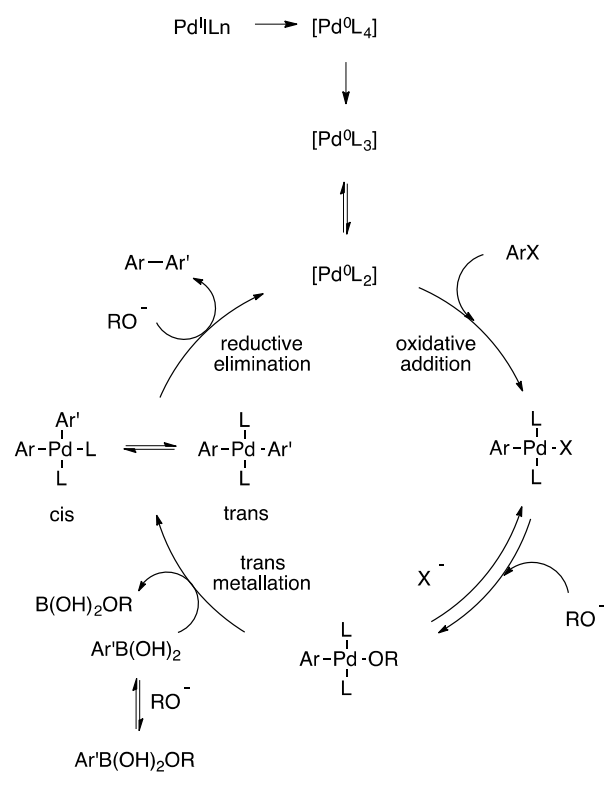

Scheme 1. Mechanism of the homogeneous Suzuki-Miyaura reaction. 
Using supported palladium catalysts, Suzuki-Miyaura cross-coupling reaction is a heterogeneous catalysis [71]. During the reaction, the palladium Pd(II) could be release from the surface of the solid support and this leaching palladium could be responsible for the catalysis as a (quasi)homogeneous mechanism (Scheme 2) [72-83].

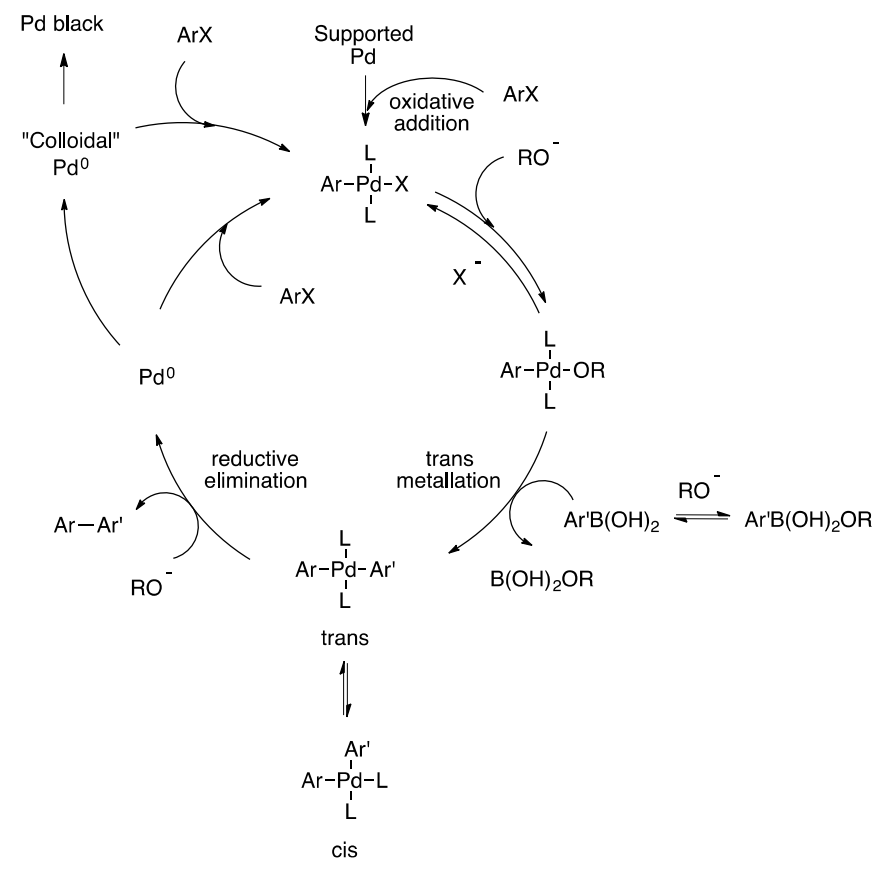

Scheme 2. Mechanism of the heterogeneous Suzuki-Miyaura reaction.

\section{Homogeneous Suzuki-Miyaura Cross-Coupling Reaction in Continuous Flow}

Buchwald reported an efficient synthesis of biaryls from aryl halide substrates using a successive lithiation/borylation/Suzuki-Miyaura cross-coupling sequence in three successive mesoreactors [84]. Starting from aryl bromide, the bromine-lithium exchange afforded the corresponding aryllithium which reacted with borate to form the boronate agent. Conventional Suzuki-Miyaura cross-coupling reaction using homogeneous second-generation palladium let precatalyst a furnished the target biaryl derivatives (Scheme 3). One of the main drawbacks of this nice concept was the formation of solids such as lithium triisopropylarylborate during the process; optimization of the nature of the solvent (THF and $\mathrm{H}_{2} \mathrm{O}$ ), the concentration of reagents and the use of acoustic irradiation have been reported to avoid the formation of such solids.

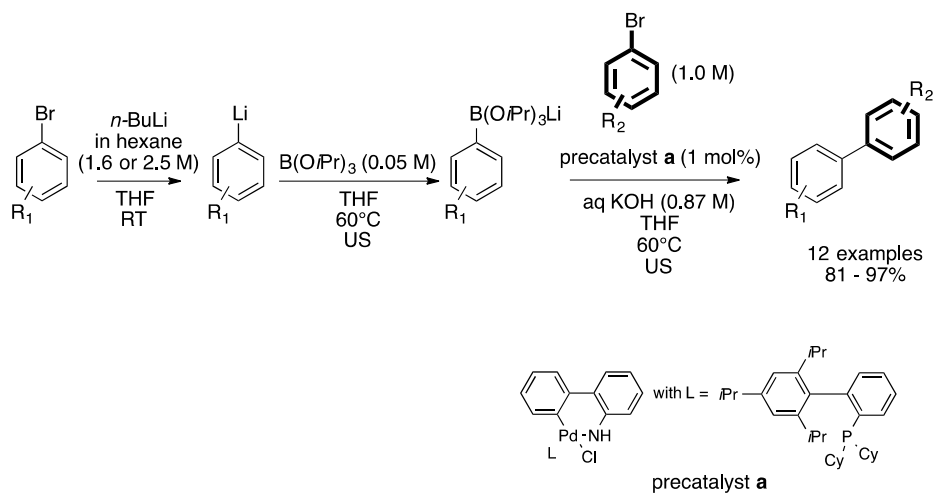

Scheme 3. Lithiation/borylation/Suzuki-Miyaura cross-coupling sequence for the synthesis of biaryl derivatives. 
In this report, the development of different reactors made with a perfluoroalkoxyalkane (PFA) tube having the inner diameter of $1 \mathrm{~mm}$ has been described [84]. A solution of arylbromide in THF and a solution of $n$-butyllithium in hexane $(1.6 \mathrm{M}$ or $2.5 \mathrm{M})$ were injected simultaneously, then mixed at a T-shaped mixer and delivered to the first reactor (reactor 1 ) at room temperature with a flow rate of $50-78 \mu \mathrm{L} \mathrm{min} \mathrm{min}^{-1}$ and a varying residence time (2-120 s). A solution of diluted $\mathrm{B}(\mathrm{OiPr})_{3}$ in THF was injected with a flow rate of $1 \mu \mathrm{L} \mathrm{min}{ }^{-1}$ and mixed with the exiting stream of aryllithium derivative at a T-shape mixer. The mixed stream was introduced to the second reactor (reactor 2) at $60{ }^{\circ} \mathrm{C}$ under acoustic irradiation with a residence time of $1 \mathrm{~min}$. Then, a solution of aqueous $\mathrm{KOH}$ $(0.87 \mathrm{M})$ and a solution of aryl halide $(1.00 \mathrm{M})$ and XPhos precatalyst $(\mathrm{a}, 1 \mathrm{~mol} \%)$ in THF were successively injected into the exiting stream with a flow rate of $100 \mu \mathrm{L} \mathrm{min}{ }^{-1}$ and $21-40 \mu \mathrm{L} \mathrm{min}{ }^{-1}$, respectively. The combined mixture was introduced to the third reactor (reactor 3) at $60{ }^{\circ} \mathrm{C}$ under acoustic irradiation with a residence time of $10 \mathrm{~min}$ (Scheme 4). Ultrasound chemistry was used for reactors 2 and 3 to avoid reactor clogging and ensure a good mixing of reagents during the formation of the borate and the Suzuki-Miyaura cross-coupling reaction.

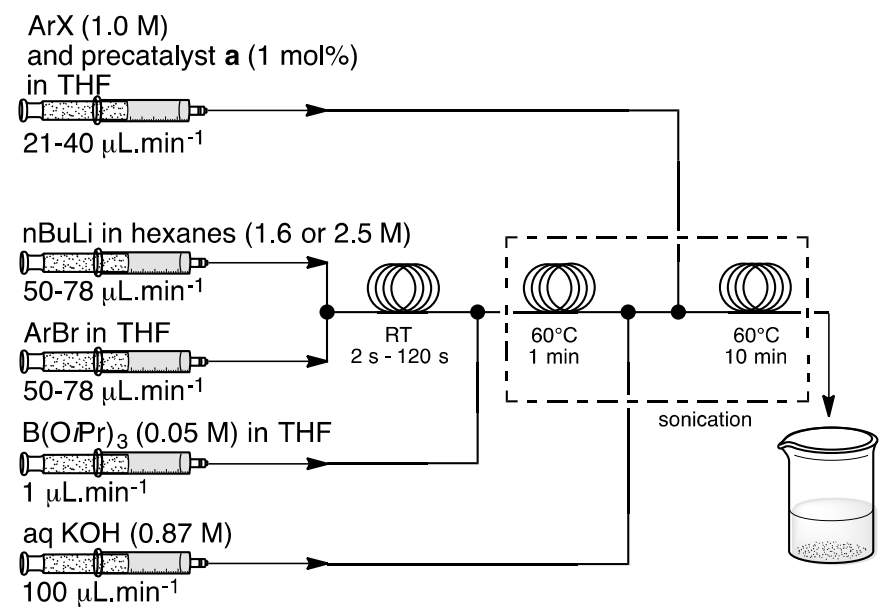

Scheme 4. Lithiation/borylation/Suzuki-Miyaura cross-coupling sequence for the synthesis of biaryl derivatives in a microflow system.

Application of the above methodology was realized with a range of various aryl halides (Figure 1), the limiting step of the process being the lithiation of aryl halides. In their hands, Buchwald described that the aryl bromide could be lithiated at room temperature. Whatever the nature of the starting aryl bromide having different electronic and steric demands in para, meta and ortho positions, the aryllithium and then the corresponding lithium arylborate were obtained in good yields. For the third step, the Suzuki-Miyaura cross-coupling reaction with aryl bromide or chloride with both electron-withdrawing and electron-donating substituents, afforded the target compounds in good yields. It was noteworthy that non-canonic heteroatomic halides such as quinoline, isoquinoline, pyrimidine and benzothiophene were good reagents for the continuous flow reaction.

It is noteworthy that five-membered 2-heteroaromatic boronic acids are unstable at room temperature and consequently give low yields in the Suzuki-Miyaura cross-coupling reaction [85-90]. Consequently, Buchwald turned attention to the lithiation/borylation/Suzuki-Miyaura cross-coupling of heteroarenes such as thiophene and furan derivatives; starting from furanic derivatives, selective deprotonation of the hydrogen atom in position 2 at room temperature afforded the corresponding lithium analog which reacted with borate to form the boronate agent. Then, conventional homogeneous Suzuki-Miyaura cross-coupling reaction furnished the target biaryl derivatives. After optimization of the first continuous flow process (Scheme 4), the borylation was made at room temperature with a reduced time (6 s vs. $60 \mathrm{~s}$ ) and acoustic irradiation was not needed for this step in reactor 2 (Scheme 5) [84]. 


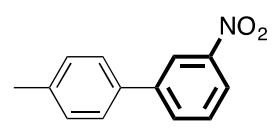

10 s, $X=B r, 90 \%$

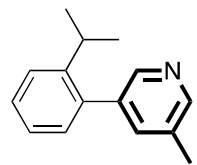

$120 \mathrm{~s}, \mathrm{X}=\mathrm{Br}, 87 \%$

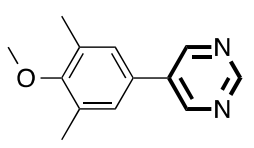

90 s, $X=B r, 97 \%$

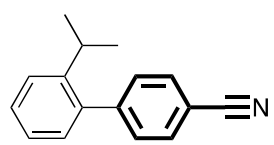

$120 \mathrm{~s}, \mathrm{X}=\mathrm{Br}, 97 \%$

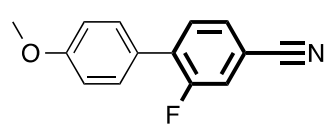

$2 \mathrm{~s}, \mathrm{X}=\mathrm{Br}, 94 \%$ [a]

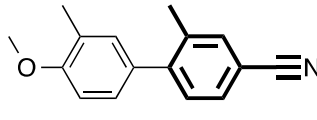

60 s, $X=B r, 81 \%$
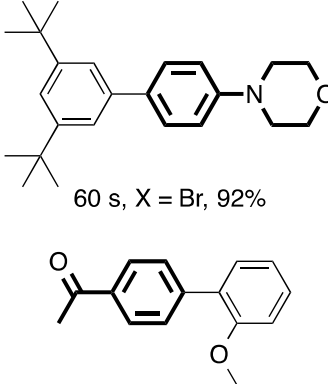

$60 \mathrm{~s}, \mathrm{X}=\mathrm{Br}, 83 \%$

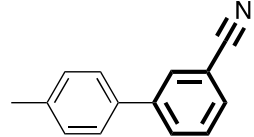

$10 \mathrm{~s}, \mathrm{X}=\mathrm{Cl}, 95 \%$

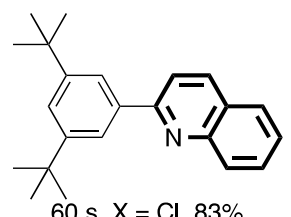

$60 \mathrm{~s}, \mathrm{X}=\mathrm{Cl}, 83 \%$

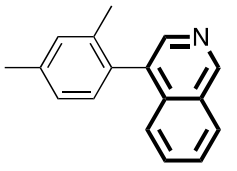

90 s, $X=B r, 96 \%$

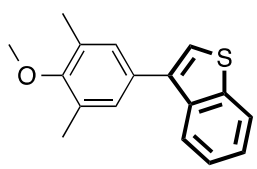

90 s, $X=B r, 84 \%$

Figure 1. Substrate scope of continuous flow lithiation/borylation/Suzuki-Miyaura cross-coupling sequence starting from aryl bromides.

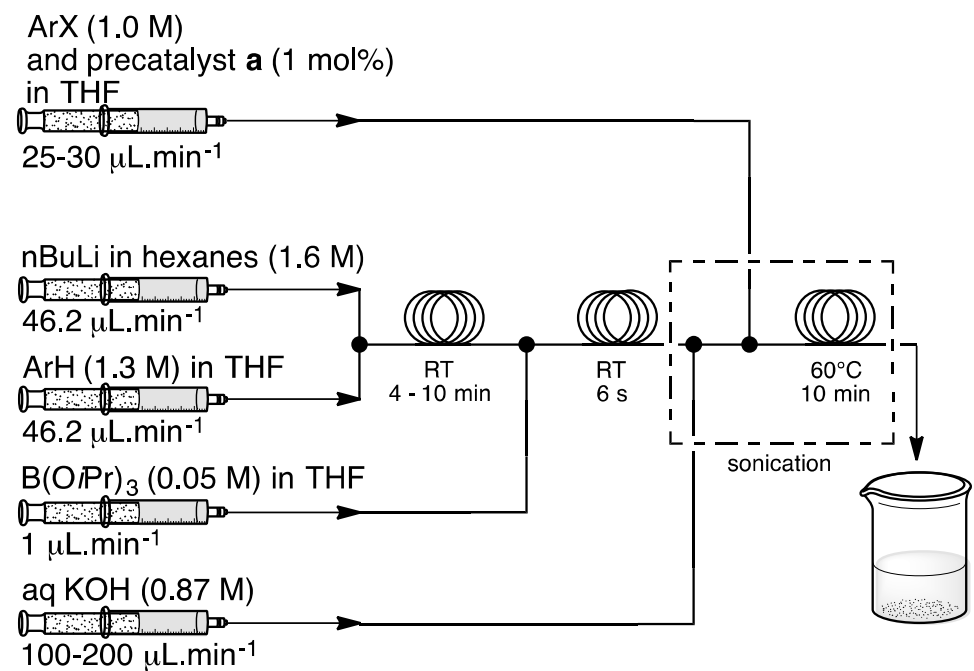

Scheme 5. Lithiation/borylation/Suzuki-Miyaura cross-coupling sequence of heteroarenes with aryl halides in a flow system.

Application of the method was realized to show the scope of the reaction [84]. Starting from thiophene, 2-alkylthiophene and 2-alkylfuran, borylation in two steps was efficient: the coupling with different substituted aryls and heteroaromatic halides afforded the target compounds in good yields (Scheme 6). This novel process allows the use of low-cost heteroarenes instead of more expensive and unstable 2-heteroaromatic boronic acids and 2-heteroaromatic bromides.

In order to illustrate the synthetic potential of this methodology, Diflunisal [91,92] was obtained in a multi-step sequence [84]. Starting from 4-bromoanisole, the lithiation/borylation followed by Suzuki-Miyaura cross-coupling with 1-bromo-2, 4-difluorobenzene permitted the synthesis of the key intermediate in the production of Diflunisal (Scheme 7). 

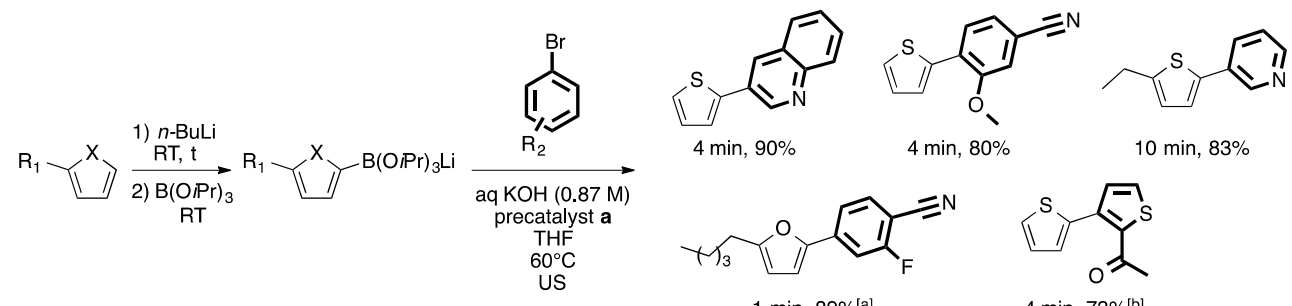

$1 \mathrm{~min}, 89 \%[\mathrm{a}]$

$4 \min , 73 \%[b]$

Scheme 6. Substrate scope of continuous flow lithiation/borylation/Suzuki-Miyaura cross-coupling sequence starting from furan derivatives: [a] $0.44 \mathrm{M} \mathrm{NaF}$ aqueous solution was used instead of $\mathrm{KOH}$; and [b] 0.87 M KF aqueous solution was used instead of $\mathrm{KOH}$.

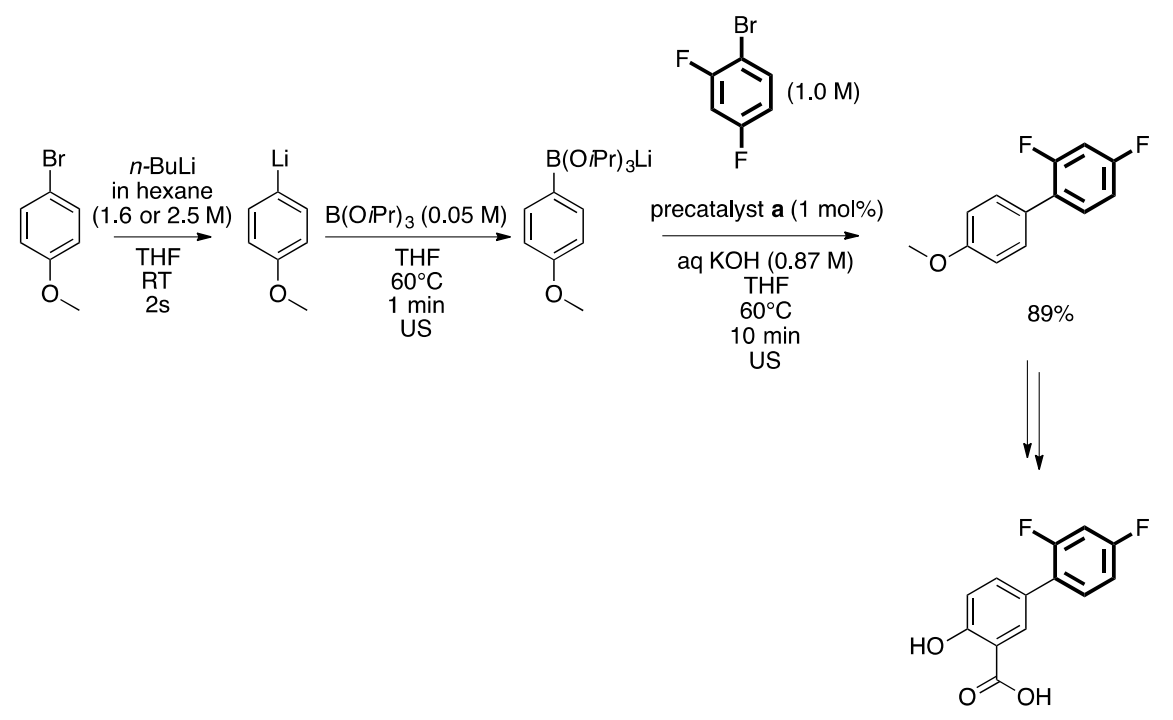

Scheme 7. Total synthesis of Diflunisal via lithiation/borylation/Suzuki-Miyaura cross-coupling in a microflow system.

In order to develop an automated, droplet-flow microfluidic system applied to Suzuki-Miyaura cross-coupling reaction, Buchwald and Jensen reported a systematic methodology including key mechanistic insights [93].

A three-step flow diazotization, iododediazotization and Suzuki-Miyaura cross coupling reaction has been reported by Organ starting from aniline derivatives [94]. Starting from the arylamine, the diazotation followed by the introduction of iodide atom furnished the iodobenzene derivatives. Then conventional Suzuki-Miyaura cross coupling afforded the biphenyl derivatives (Scheme 8).

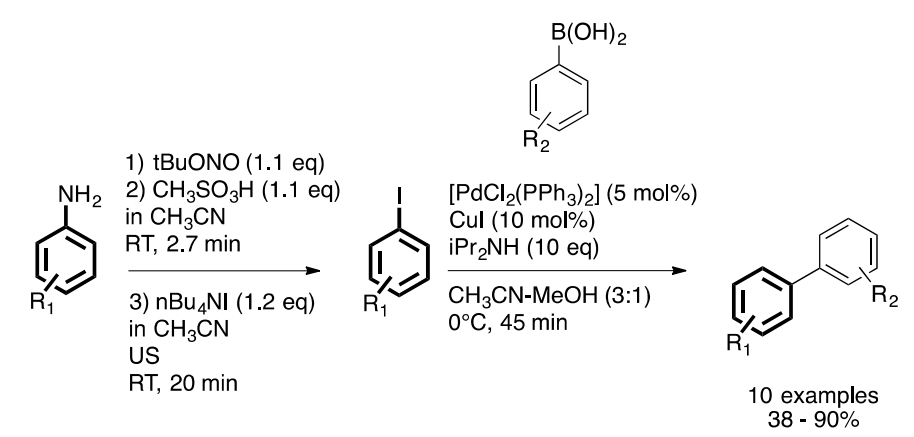

Scheme 8. Diazotization/iododediazotization/Suzuki-Miyaura cross coupling sequence for the synthesis of biaryl derivatives. 
Three reactors were made with PFA capillary tubing with an inner diameter of $1.52 \mathrm{~mm}$ and different volumes. The residence time in reactors was adjusting the length of the reactor tubing. A solution of aniline derivative in $\mathrm{CH}_{3} \mathrm{CN}$ and a solution of $\mathrm{tBuONO}$ in $\mathrm{CH}_{3} \mathrm{CN}$ were injected simultaneously, followed by mixing with a T-mixer and injection of a solution of methanesulfonic acid in $\mathrm{CH}_{3} \mathrm{CN}$. The three solutions were used with a flow rate of $22 \mu \mathrm{L} \mathrm{min}{ }^{-1}$. The mixed stream was introduced to the first reactor at room temperature with a residence time of $2.7 \mathrm{~min}$. Then, a solution of $\mathrm{nBuNI}$ in $\mathrm{CH}_{3} \mathrm{CN}$ was injected into the stream with the same flow. The combined mixture was introduced to the second reactor for which is immersed in an ultrasonic bath. The residence time was $20 \mathrm{~min}$ at room temperature and then the segmented effluent was temporarily collected in an intermediate reservoir. Due to the used reservoir a continuous flow unit (CFU) was accommodated. A solution of $\left[\mathrm{PdCl}_{2}\left(\mathrm{PPh}_{3}\right)_{2}\right]$, $\mathrm{CuI}, i \mathrm{Pr}_{2} \mathrm{NH}$ in $\mathrm{CH}_{3} \mathrm{CN}$ and a solution of boronic acid in $\mathrm{MeOH}$ were injected simultaneously to the main stream and introduced to the third reactor at $60^{\circ} \mathrm{C}$ for $45 \mathrm{~min}$ (Scheme 9) [94].

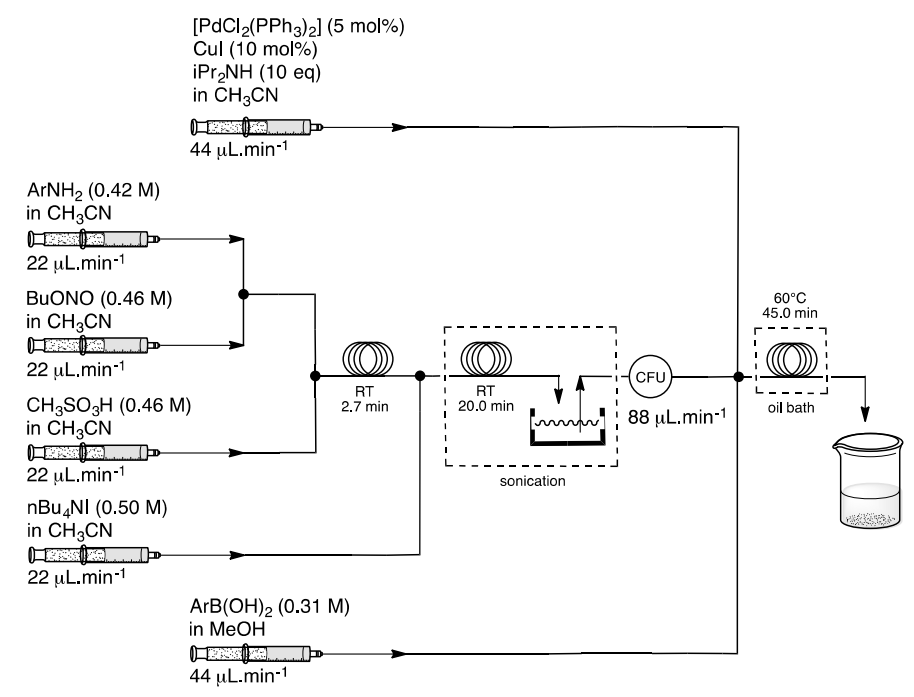

Scheme 9. Diazotization/iododediazotization/Suzuki-Miyaura cross-coupling sequence of aniline derivative with aryl halides in a flow system.

Application of the above protocol with little variations to the production of biphenyl compounds was reported (Figure 2). In function of the different steric and electric demands in the aromatic core, the coupling gave satisfactory yields [94].

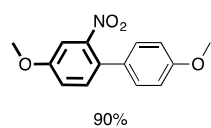

$90 \%$
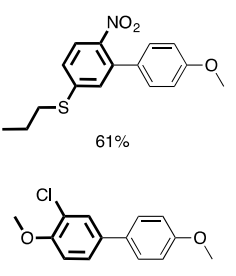

$65 \%$

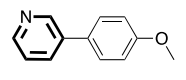

$70 \%$

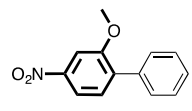

$82 \%$
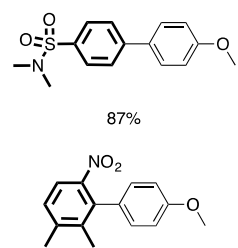

$38 \%$

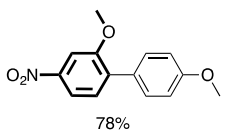

$78 \%$

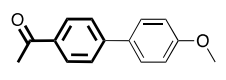

$76 \%$

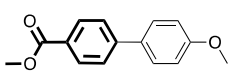

$69 \%$

Figure 2. Substrate scope of continuous flow diazotization/iododediazotization/Suzuki-Miyaura cross-coupling sequence starting from aniline derivative. 
Application to continuous flow process on a large scale was reported recently and could open new way for industrial use $[95,96]$.

\section{Heterogeneous Suzuki-Miyaura Cross-Coupling Reaction in Continuous Flow}

A suitable solid support having $\mathrm{Pd}(\mathrm{II})$ species precursors to $\mathrm{Pd}(0)$ catalysts are now commercially available but different groups prefer to design their home-made catalysts. In the first part the use of $\operatorname{Pd}(0)$ reagent is reported and in the second part $\mathrm{Pd}(\mathrm{II})$ is described.

Monguchi and Sajiki reported a palladium on carbon-catalyzed Suzuki-Miyaura coupling reaction using an efficient and continuous flow system (Scheme 10) [97]. To investigate the scope of the reaction, a range of arylboronic acids and halogenobenzene derivatives were tested in mild conditions for $20 \mathrm{~s}$ during a single-pass (Figure 3). The authors have reported the detection of little leaching ( $<1 \mathrm{ppm})$.

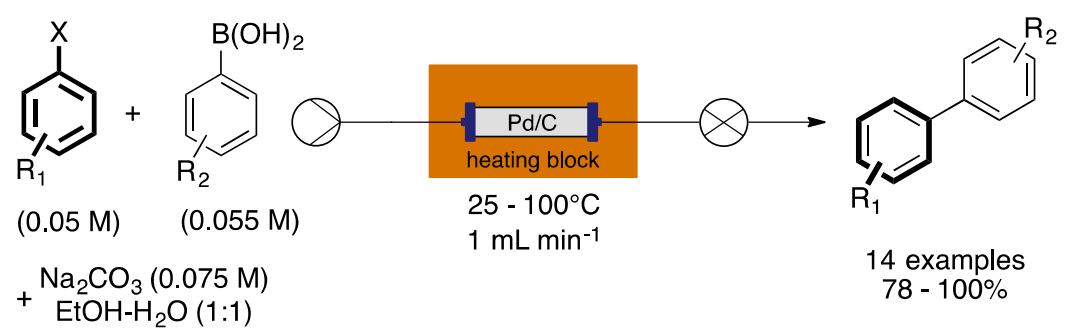

Scheme 10. Suzuki-Miyaura cross coupling in a flow system using H-Cube ${ }^{\circledR}$.

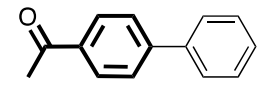

$X=I, T=25^{\circ} \mathrm{C}, 76 \%$ $\mathrm{X}=\mathrm{Br}, \mathrm{T}=50^{\circ} \mathrm{C}, 90 \%$

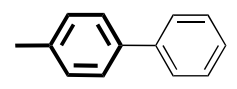

$X=I, T=75^{\circ} \mathrm{C}, 91 \%$

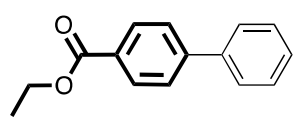

$X=I, T=25^{\circ} \mathrm{C}, 92 \%$ $\mathrm{X}=\mathrm{Br}, \mathrm{T}=100^{\circ} \mathrm{C}, 78 \%$

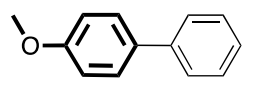

$X=I, T=75^{\circ} \mathrm{C}, 81 \%$

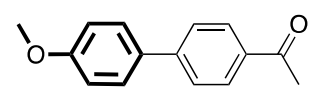

$X=I, T=75^{\circ} \mathrm{C}, 97 \%$

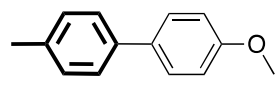

$X=I, T=75^{\circ} \mathrm{C}, 100 \%$

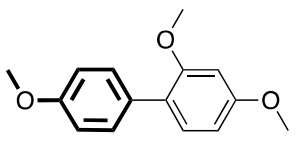

$X=I, T=100^{\circ} \mathrm{C}, 78 \%$

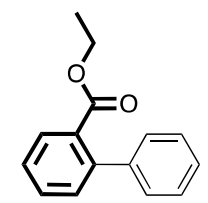

$X=I, T=75^{\circ} \mathrm{C}, 88 \%$

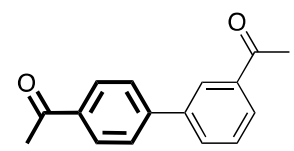

$X=I, T=25^{\circ} \mathrm{C}, 99 \%$

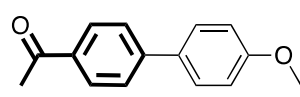

$X=I, T=50^{\circ} \mathrm{C}, 89 \%$

$\mathrm{X}=\mathrm{Br}, \mathrm{T}=50^{\circ} \mathrm{C}, 97 \%$

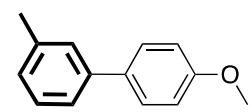

$X=I, T=75^{\circ} \mathrm{C}, 88 \%$

$X=I, T=75^{\circ} \mathrm{C}, 97 \%$

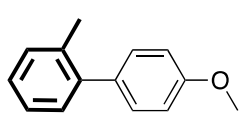

$X=I, T=75^{\circ} \mathrm{C}, 98 \%$

Figure 3. Substrate scope of continuous flow Suzuki-Miyaura cross-coupling sequence in a flow system using H-Cube ${ }^{\circledR}$. 
Using the same apparatus $\mathrm{H}$-Cube ${ }^{\circledR}$, another group reported the Suzuki-Miyaura cross coupling in the presence of graphene supported palladium nanoparticles [98]. A solution of 4-bromobenzaldehyde and phenylboronic acid dissolved in $\mathrm{H}_{2} \mathrm{O}-\mathrm{EtOH}-\mathrm{THF}$ (1:1:1) was injected with a flow rate of $0.2 \mathrm{~mL} \mathrm{~min}^{-1}$ resulting in a contact time of less than $1 \mathrm{~min}$ at $135^{\circ} \mathrm{C}$. The target biaryl compound was obtained in good yield with a conversion of $96 \%$ (Scheme 11).

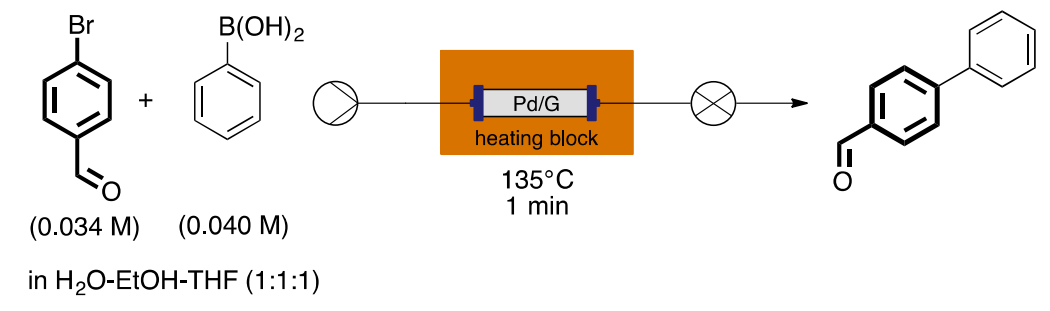

Scheme 11. Suzuki-Miyaura cross coupling in a flow system using $\mathrm{H}-\mathrm{Cube}{ }^{\circledR}$.

In 2006, Canty was the first to develop a macroporous monolith support as a suitable substrate for anchoring a palladium complex for Suzuki-Miyaura cross-coupling continuous flow capillary microreactors [99]. Ten years after, Nagaki reported an efficient three-step flow sequence using Pd catalyst [100]. The aryllithium obtained from arylbromide reacted with $\mathrm{B}(\mathrm{OMe})_{3}$; after the borylation reaction, the Suzuki-Miyaura cross coupling reaction in the presence of immobilized $\operatorname{Pd}(0)$ on the polymer afforded the target biaryl derivatives (Scheme 12).

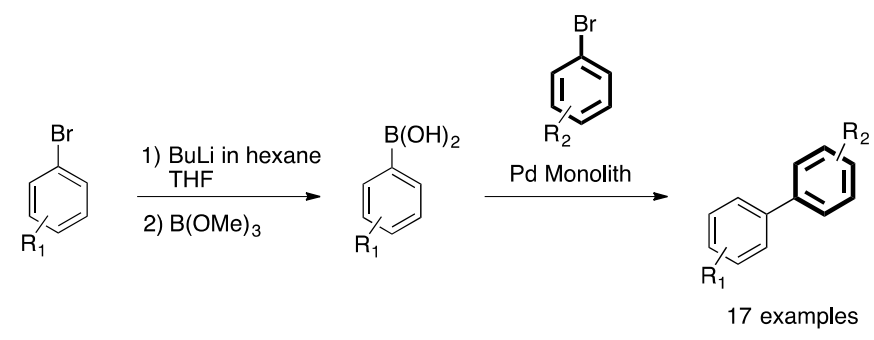

Scheme 12. Halogen/lithium exchange/borylation/Suzuki-Miyaura cross-coupling sequence for the synthesis of biaryl derivatives.

In this report, a solution of bromobenzene in THF $(0.10 \mathrm{M})$ and a solution n-BuLi $(0.6 \mathrm{M}$ in hexane) were injected simultaneously with a flow rate of $6.0 \mathrm{~mL} \mathrm{~min}^{-1}$ and $1 \mathrm{~mL} \mathrm{~min}^{-1}$, respectively, in a micromixer $(\mathrm{ID}=500 \mu \mathrm{m})$ and then in a reactor $(\mathrm{ID}=1000 \mu \mathrm{m})$ for a residence time of $1.7 \mathrm{~s}$. A solution of diluted $\mathrm{B}(\mathrm{OMe})_{3}(0.12 \mathrm{M})$ in THF was injected with a flow rate of $6.0 \mathrm{~mL} \mathrm{~min}^{-1}$ and the main stream was introduced to a micromixer (ID $=500 \mu \mathrm{m}$ ) and the second reactor (ID $=1000 \mu \mathrm{m}$ ) for a residence time of $2.0 \mathrm{~s}$ (Scheme 13). After producing the boronic acid solution, iodoaryl derivative $(0.33 \mathrm{M})$ in methanol was added and the mixture was passed through the palladium catalyst at $100^{\circ} \mathrm{C}$ with a residence time of $4.7 \mathrm{~min}$ or at $120^{\circ} \mathrm{C}$ with a residence time of $9.4 \mathrm{~min}$. 


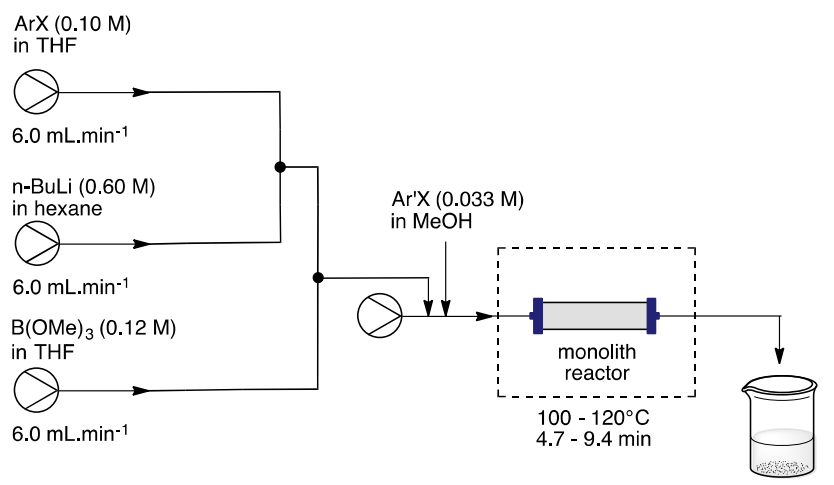

Scheme 13. Halogen/lithium exchange/borylation/Suzuki-Miyaura cross-coupling sequence for the synthesis of biaryl derivatives in a microflow system.

Application of the above methodology was successfully applied to the cross-coupling of various functional aryl and heteroaryl iodides (Figure 4) [100]. It was noticeable that cyano derivatives in this process tolerated the experimental conditions. Adapalene, a drug used for the treatment of acne, was produced in $86 \%$ yield by applying this methodology.

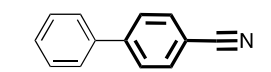

$\mathrm{T}=100^{\circ} \mathrm{C}, \mathrm{rt}=4.7 \mathrm{~min}, 96 \%$ $\mathrm{T}=120^{\circ} \mathrm{C}, \mathrm{rt}=9.4 \mathrm{~min}, 100 \%$

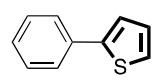

$\mathrm{T}=100^{\circ} \mathrm{C}, \mathrm{rt}=4.7 \mathrm{~min}, 86 \%$

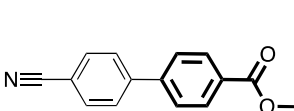

$\mathrm{T}=100^{\circ} \mathrm{C}, \mathrm{rt}=4.7 \mathrm{~min}, 34 \%$
$T=120^{\circ} \mathrm{C}, \mathrm{rt}=9.4 \mathrm{~min}, 84 \%$

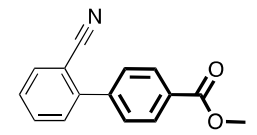

$\mathrm{T}=100^{\circ} \mathrm{C}, \mathrm{rt}=4.7 \mathrm{~min}, 2 \%$

$\mathrm{T}=120^{\circ} \mathrm{C}, \mathrm{rt}=9.4 \mathrm{~min}, 53 \%$

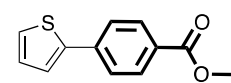

$\mathrm{T}=100^{\circ} \mathrm{C}, \mathrm{rt}=4.7 \mathrm{~min}, 71 \%$

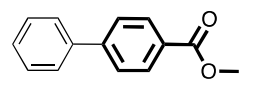

$\mathrm{T}=100^{\circ} \mathrm{C}, \mathrm{rt}=4.7 \mathrm{~min}, 76 \%$
$\mathrm{~T}=120^{\circ} \mathrm{C}, \mathrm{rt}=9.4 \mathrm{~min}, 87 \%$

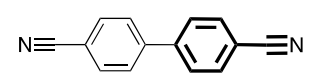

$\mathrm{T}=100^{\circ} \mathrm{C}, \mathrm{rt}=4.7 \mathrm{~min}, 68 \%$

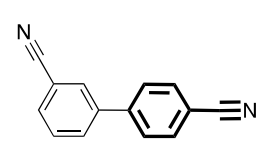

$\mathrm{T}=100^{\circ} \mathrm{C}, \mathrm{rt}=4.7 \mathrm{~min}, 63 \%$
$\mathrm{~T}=120^{\circ} \mathrm{C}, \mathrm{rt}=9.4 \mathrm{~min}, 97 \%$

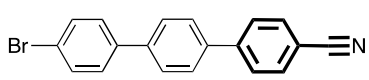

$\mathrm{T}=100^{\circ} \mathrm{C}, \mathrm{rt}=4.7 \mathrm{~min}, 0 \%$

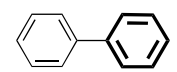

$\mathrm{T}=100^{\circ} \mathrm{C}, \mathrm{rt}=4.7 \mathrm{~min}, 6 \%$ $\mathrm{T}=120^{\circ} \mathrm{C}, \mathrm{rt}=9.4 \mathrm{~min}, 41 \%$

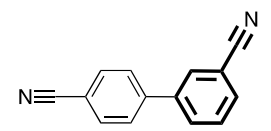

$\mathrm{T}=100^{\circ} \mathrm{C}, \mathrm{rt}=4.7 \mathrm{~min}, 17 \%$

$\mathrm{T}=120^{\circ} \mathrm{C}, \mathrm{rt}=9.4 \mathrm{~min}, 83 \%$

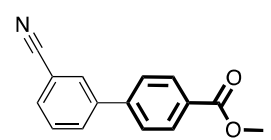

$\mathrm{T}=100^{\circ} \mathrm{C}, \mathrm{rt}=4.7 \mathrm{~min}, 15 \%$

$T=100^{\circ} \mathrm{C}, r t=4.7 \mathrm{~min}, 15 \%$
$T=120^{\circ} \mathrm{C}, \mathrm{rt}=9.4 \mathrm{~min}, 87 \%$

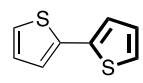
$T=100^{\circ} \mathrm{C}, \mathrm{rt}=4.7 \mathrm{~min}, 83 \%$
$T=120^{\circ} \mathrm{C}, \mathrm{rt}=9.4 \mathrm{~min}, 94 \%$

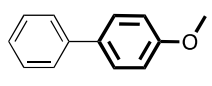

$\mathrm{T}=100^{\circ} \mathrm{C}, \mathrm{rt}=4.7 \mathrm{~min}, 1 \%$

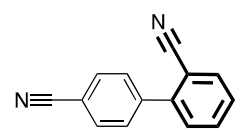

$\mathrm{T}=100^{\circ} \mathrm{C}, \mathrm{rt}=4.7 \mathrm{~min}, 12 \%$

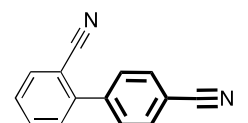

$\mathrm{T}=100^{\circ} \mathrm{C}, \mathrm{rt}=4.7 \mathrm{~min}, 63 \%$
$\mathrm{~T}=120^{\circ} \mathrm{C}, \mathrm{rt}=9.4 \mathrm{~min}, 98 \%$

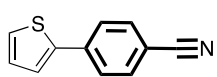

$\mathrm{T}=100^{\circ} \mathrm{C}, \mathrm{rt}=4.7 \mathrm{~min}, 78 \%$

Figure 4. Substrate scope of continuous flow lithiation/borylation/Suzuki-Miyaura cross-coupling sequence in a flow system using immobilized Pd on polymer monolith.

A large-scale Suzuki-Miyaura cross-coupling reaction using solid supported palladium $\mathrm{Pd}^{0}$ nano/microparticles and ultrasound irradiation was reported in continuous flow by Das [101]. The continuous flow technique used by the authors required a syringe, a reservoir, a pump and a reaction vessel. After the introduction of the aryl bromide, phenylboronic acid and potassium carbonate in $\mathrm{MeOH}-\mathrm{H}_{2} \mathrm{O}$ in the reservoir via the syringe $\mathbf{a}$, the reagents were pumped $\left(127 \mathrm{~mL} \mathrm{~min}{ }^{-1}\right)$ to the reaction vessel e where the solid supported palladium (0) nano/microparticles (SS-Pd) as 
heterogeneous catalyst had been charged. Ultrasonication of the mixture $(20 \mathrm{kHz})$ was realized and the reaction product was poured through $\mathbf{b}$ into the reservoir. Two exits ( $\mathbf{d}$ and $\mathbf{g}$ ) were present to recover the mixture after completion of the reaction (Scheme 14). In comparison with microreactor and mesoreactor, this process permitted to furnish biaryl derivatives on a gram scale in continuous flow.

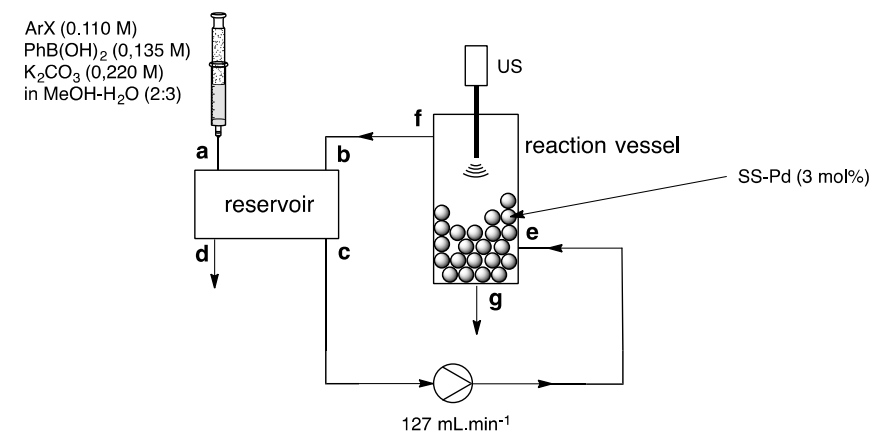

Scheme 14. Continuous flow Suzuki-Miyaura cross-coupling on a gram scale of the substrate.

Reactions of various aryl iodides with phenylboronic acids gave excellent yields. Aryl iodides having different substituents were explored without significant change in their reactivity. The activation of the aryl chloride was more difficult than expected, but gave good yields using this methodology (Scheme 15) [101].
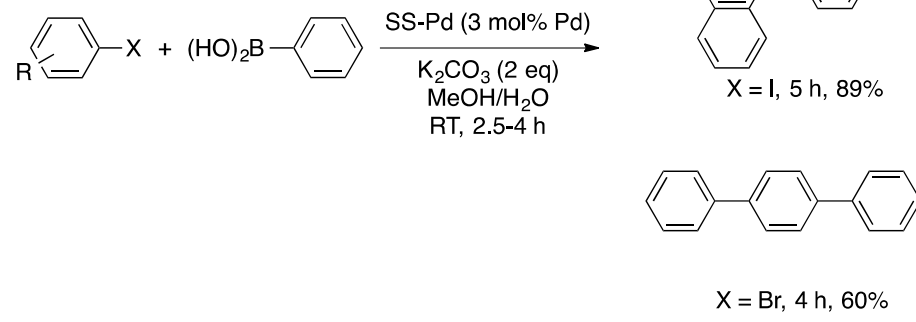
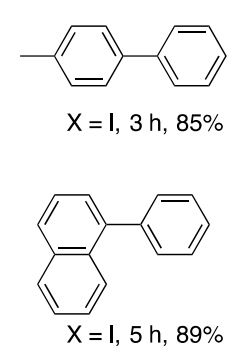

$\mathrm{X}=\mathrm{Br}, 4 \mathrm{~h}, 60 \%$

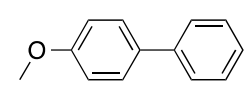

$\mathrm{X}=\mathrm{I}, 3 \mathrm{~h}, 92 \%$ $\mathrm{X}=\mathrm{Br}, 4 \mathrm{~h}, 71 \%$ $\mathrm{X}=\mathrm{Br}, 3,26 \%$
$\mathrm{X}=\mathrm{h}, \mathrm{h}$

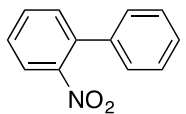

$\mathrm{X}=\mathrm{I}, 2.5 \mathrm{~h}, 92 \%$ $X=I, 2.5 \mathrm{~h}, 92 \%$
$X=\mathrm{Cl}, 3.5 \mathrm{~h}, 62 \%$

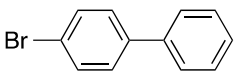

$X=I, 3 \mathrm{~h}, 92 \%$
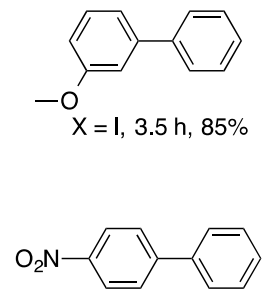

$X=I, 3 \mathrm{~h}, 89 \%$

$\mathrm{X}=\mathrm{Br}, 10 \mathrm{~h}, 82 \%$ $\mathrm{X}=\mathrm{Cl}, 3.5,87 \%$

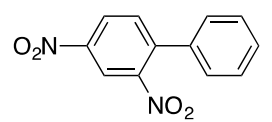

$\mathrm{X}=\mathrm{Cl}, 3 \mathrm{~h}, 53 \%$

Scheme 15. Continuous flow Suzuki-Miyaura cross-coupling reaction of phenyl boronic acid with aryl halides using SS-Pd as heterogeneous catalyst.

The catalytic stability in $\mathrm{MeOH}-\mathrm{H}_{2} \mathrm{O}$ under flow conditions was studied by Das and a mechanism was proposed (Scheme 16) [101]. No significant loss of activity was observed after recycling five times. In their hands, the SEM analysis of SS-Pd showed the presence of $\operatorname{Pd}(0)$ nano-microparticulates on the solid support which implies its reusability and minimum leaching of Pd from the solid surface. 


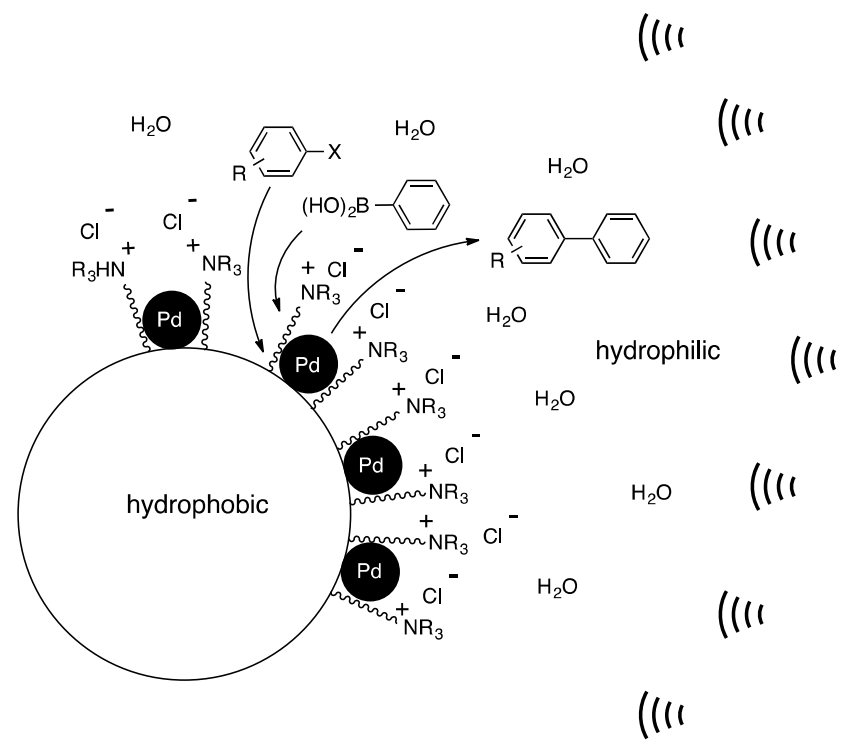

Scheme 16. A schematic diagram of the Suzuki-Miyaura cross-coupling reaction of phenyl boronic acid with aryl halides using SS-Pd as heterogeneous catalyst.

Martin-Matute developed a novel strategy using Pd nanoparticles supported in a functionalized mesoporous Metal-Organic Frameworks (MOFs) [102]. To the best of our knowledge, it was the first report on the use of metallic nanoparticles supported on MOFs in flow chemistry for catalytic applications. A mixture of aryl halide, boronic acid/ester and $\mathrm{K}_{2} \mathrm{CO}_{3}$ in water and ethanol was passed through a column of homemade $8 \mathrm{wt} \%$ Pd@MIL-101- $\mathrm{NH}_{2}$ at room temperature for a residence time of 35-40 min (Scheme 17).

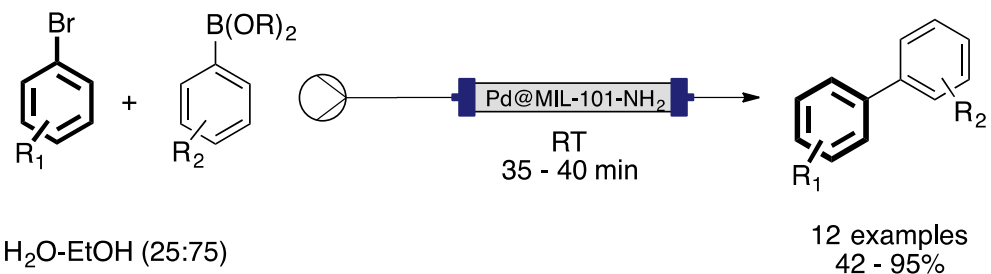

Scheme 17. Suzuki-Miyaura cross coupling in a flow system using Pd MOF.

Variations of the aryl halides and boronic acid derivatives permitted the production of a mini-library (Figure 5). The authors always used the same cartridge for the preparation of the mini-library of biaryl derivatives. It is noticeable that after the reaction, the recovery catalyst was found to be partially crystalline with a remaining Pf content of $6.81 \mathrm{wt} \%$ (initially $7.29 \mathrm{wt} \%$ ) [102]. 


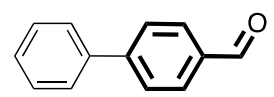

$Y=\operatorname{Pin}, 95 \%$

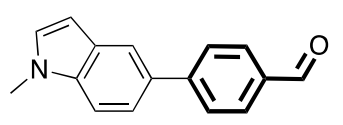

$Y=P$ in, $85 \%$

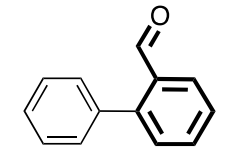

$\mathrm{Y}=\mathrm{Pin}, 82 \%$

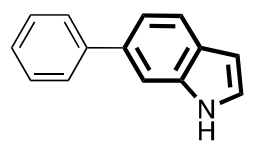

$Y=P$ in, $84 \%$

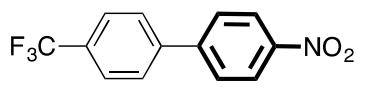

$\mathrm{Y}=(\mathrm{OH})_{2}, 95 \%$

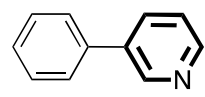

$Y=P$ in, $85 \%$

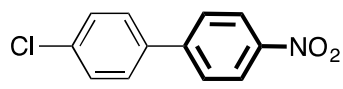

$\mathrm{Y}=(\mathrm{OH})_{2}, 91 \%$

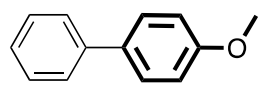

$\mathrm{Y}=\mathrm{Pin}, 80 \%$

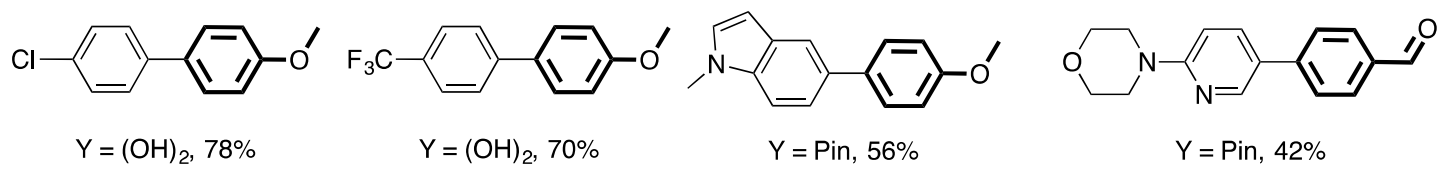

Figure 5. Substrate scope of continuous flow Suzuki-Miyaura cross-coupling sequence using immobilized Pd on MOFs.

A very nice strategy based on dendrimer-encapsulated Pd nanoparticles as catalyst in flow reactor was developed by Verboom $[103,104]$. In contrast with the conventional heterogeneous Suzuki-Miyaura cross-coupling reaction using cartridge filled with solid catalysts, Verboom's method anchored Pd nanoparticles onto the inner walls of the flow reactor. Aryl halides $(10 \mathrm{mM})$ were mixed with boronic acid derivatives $(15 \mathrm{mM})$ in ethanol at $80{ }^{\circ} \mathrm{C}$ using $\mathrm{n}-\mathrm{Bu} \mathrm{u}_{4} \mathrm{NOH}(20 \mathrm{mM})$ as base at $80{ }^{\circ} \mathrm{C}$. The solution was passed through the catalytic microreactor with a residence time of $13 \mathrm{~min}$ (Scheme 18).

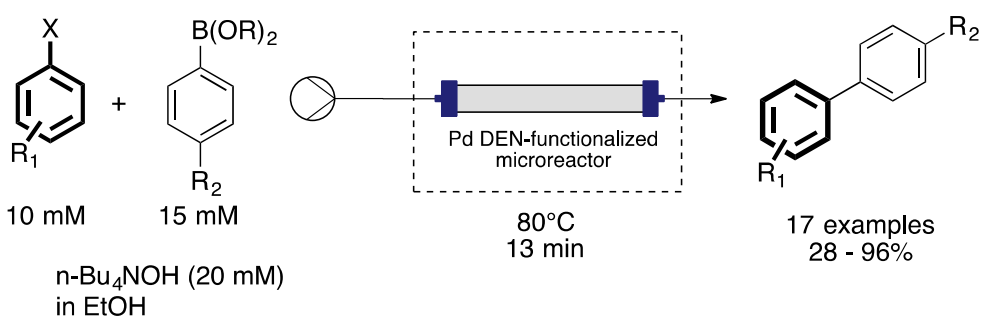

Scheme 18. Suzuki-Miyaura cross coupling in a flow system using dendrimer-encapsulated Pd nanoparticles.

The electronic substituents effects have been studied and different biaryl compounds have been obtained (Figure 6). This strategy demonstrated the influence of dendrimers in the stabilization of the Pd NPs with low metal leaching [103,104]. 


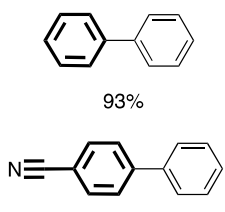

$96 \%$

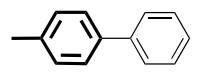

$70 \%$

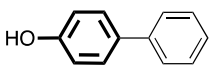

$30 \%$

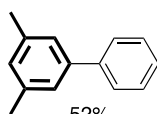

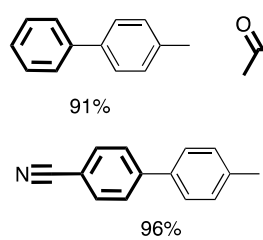

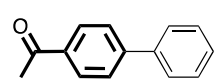

$92 \%$

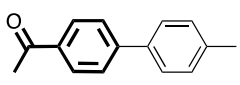

$91 \%$
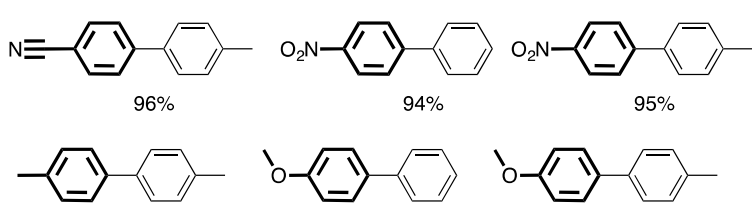

$65 \%$

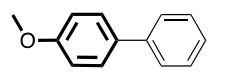

$65 \%$

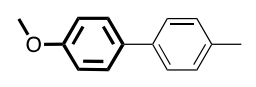

$60 \%$

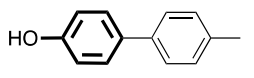

$28 \%$

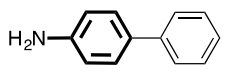

$50 \%$

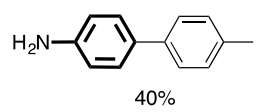

$40 \%$

Figure 6. Substrate scope of continuous flow Suzuki-Miyaura cross-coupling sequence using Pd dendrimers encapsulated microreactor.

Another group developed dendrimers for continuous flow Suzuki-Miyaura cross-coupling reaction [105]. Variation was noticeable since the authors described magnetic $\mathrm{Fe}_{3} \mathrm{O}_{4}$ fixation of dendron-functionalized iron oxide nanoparticles containing Pd nanoparticles. In this process, the non-covalent magnetic fixation of solid material inside the glass reactor microstructures was applied using external magnetic forces and the reversible immobilization of catalyst materials onto the wall of microchannels was possible. Application of this methodology was realized to produce only one compound using 4-methoxy-1-bromobenzene and boronic acid.

Another strategy used palladium nanoparticles immobilized in a polymer membrane for the Suzuki-Miyaura cross-coupling reaction but this particular area has not been developed in this review. As examples, some works have been written recently in this field and are just quoted in this review for interested researchers wishing to gain deeper knowledge of the field [106-108].

Alcazar reported an efficient cross-coupling reaction using commercial heterogeneous silica-supported palladium catalyst and a mesoreactor [109]. The authors used a simple and efficient experimental set-up using a $6.6 \mathrm{~mm}$ (internal diameter) Omnifit column containing $1 \mathrm{~g}$ of heterogeneous catalyst and commercial boronic acids and aryl halides (Scheme 19). A solution of aryl halide in THF and a solution of boronic acid and base in water were pumped at $0.2 \mathrm{~mL} \mathrm{~min}^{-1}$ with two independent pumps. The flow streams met at a T-shaped mixer and then passed through a column containing SiliaCat DPP-Pd as diphenylphosphine palladium (II) heterogeneous catalyst at $60{ }^{\circ} \mathrm{C}$ with a residence time of $5 \mathrm{~min}$. A biphasic solvent system such as THF- $\mathrm{H}_{2} \mathrm{O}$ was used to ensure complete dissolution of any solid and avoiding any subsequent clogging.

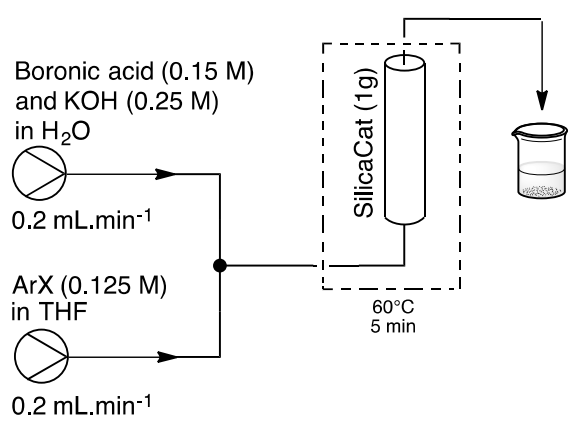

Scheme 19. Continuous flow Suzuki-Miyaura cross-coupling sequence using SiliaCat DPPP-Pd as supported catalyst. 
Application of this strategy permitted the synthesis of the biaryl derivatives starting from halides/pseudohalides and (4-methoxyphenyl) boronic acid in excellent yields (Scheme 20) [109]. Whatever the leaving group on the benzene ring, the target biphenyl derivatives were obtained in high yields. Of course, the use of aromatic ring bearing electron-donor groups such as 2,4-dimethoxy analogs gave lower yields $(50 \%)$. It was notable that bromo- and chloropyridines provided good yields and the ester functionality was tolerated despite the use of $\mathrm{KOH}$ as strong base. Using this process, the authors claimed that the crude products are clean and free of phosphine ligand avoiding the need of chromatographic purification. Moreover, low leaching of palladium from the support and the stability of the catalyst after more than 30 cycles was observed.

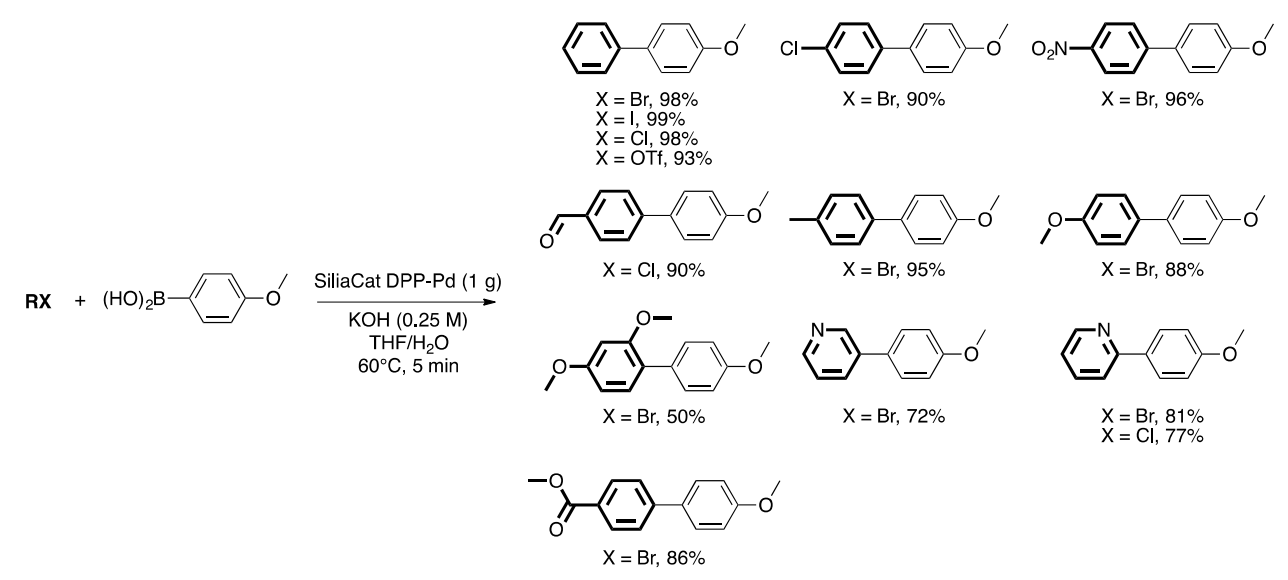

Scheme 20. Substrate scope of continuous flow Suzuki-Miyaura cross-coupling sequence with different aryl bromides and 4-methoxyphenylboronic acid.

In order to further explore the scope of the reaction, Alcazar reported the use of bromobenzene and phenyltriflate as starting materials with different boronic acid derivatives (Scheme 21) [109]. Excellent yields were obtained with commercial boronic acids and boronic ester, borane and borate freshly prepared from the corresponding bromo derivatives by metalation [110].

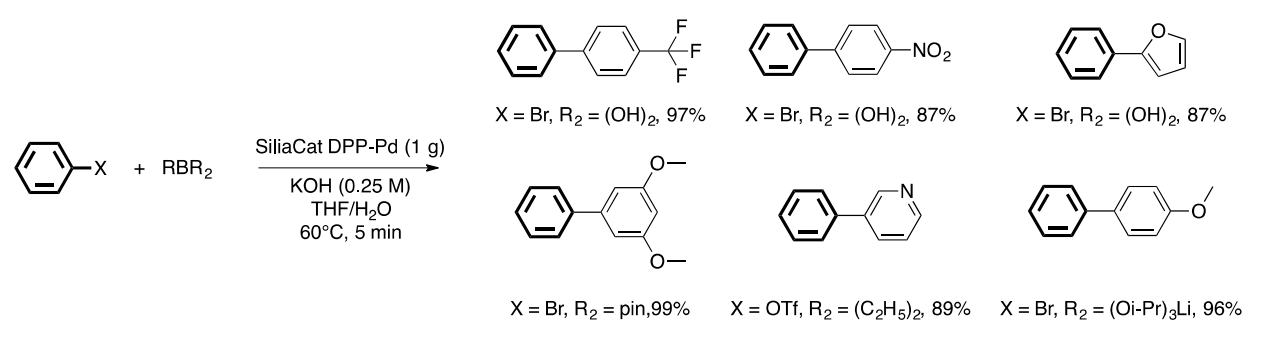

Scheme 21. Substrate scope of continuous flow Suzuki-Miyaura cross-coupling reaction with different aryl bromides/triflate and phenylboronic acid derivatives.

Recently, Kappe presented a comparative investigation of four commercial immobilized phosphine-based Pd catalyst [111]. One of them was SiliaCat DPP-Pd as diphenylphosphine palladium (II) heterogeneous catalyst developed by Pagliaro [112-114]. In this work, the best process used two stock solutions. The first solution contained aryl halide $(0.83 \mathrm{M})$ in THF and the second one phenylboronic acid $(0.45 \mathrm{M})$ and $\mathrm{K}_{2} \mathrm{CO}_{3}(0.55 \mathrm{M})$ in a mixture of $\mathrm{H}_{2} \mathrm{O}-\mathrm{EtOH}(1: 1)$. These two solutions were pumped in different feeds, $0.055 \mathrm{~mL} \mathrm{~min}^{-1}$ and $0.155 \mathrm{~mL} \mathrm{~min}^{-1}$, respectively, and mixed in a T-mixer and then introduced to the catalyst cartridge of the $\mathrm{X}$-cube flow reactor at $80^{\circ} \mathrm{C}$ (Scheme 22). Under these conditions, full conversion was obtained in less than $20 \mathrm{~min}$ and almost quantitative yield of the biaryl target compound was reported. 


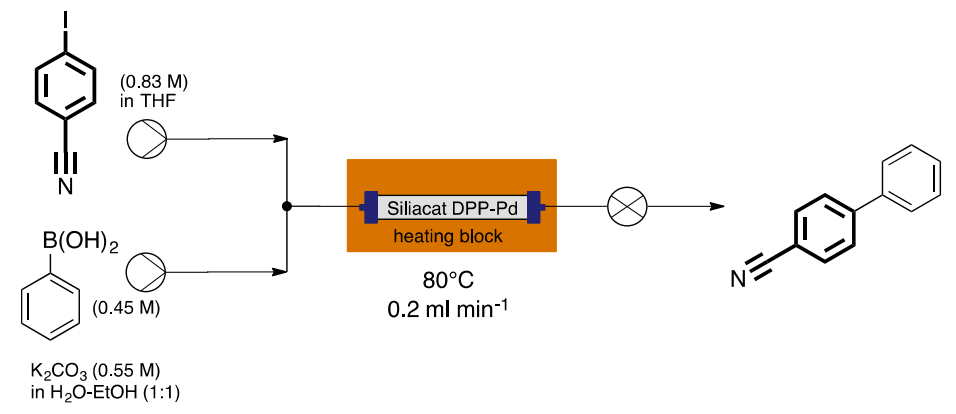

Scheme 22. Suzuki-Miyaura cross coupling in a flow system X-Cube using commercial Siliacat DPP-Pd.

Buarque and Esteves reported an interesting work using heterogeneous catalyst from Covalent Organic Frameworks (COFs) [115], COFs are different than MOFs since COFs do not contain metallic ions or heavy elements as part of their structures. In this study, the authors developed $\mathrm{Pd}(\mathrm{OAc})_{2} @ \mathrm{COF}-300$ for the Suzuki-Miyaura cross-coupling reaction in continuous flow (Scheme 23). The mixture of bromobenzene, phenylboronic acid in a solution of $\mathrm{MeONa}(2 \mathrm{M})$ in $\mathrm{MeOH}$ was injected on to a glass column (Omnifit column with a volume of $6.3 \mathrm{~mL}$ ), which was filled with glass beads $(2 \mathrm{~mm})$ and $\mathrm{Pd}(\mathrm{OAc})_{2} @ \mathrm{COF}-300(100 \mathrm{mg})$. The residence time was $20 \mathrm{~min}$ and the temperature was maintained at $60^{\circ} \mathrm{C}$; under these conditions, the maximal conversion was obtained between 20 and 40 min with a very high degree of selectivity.
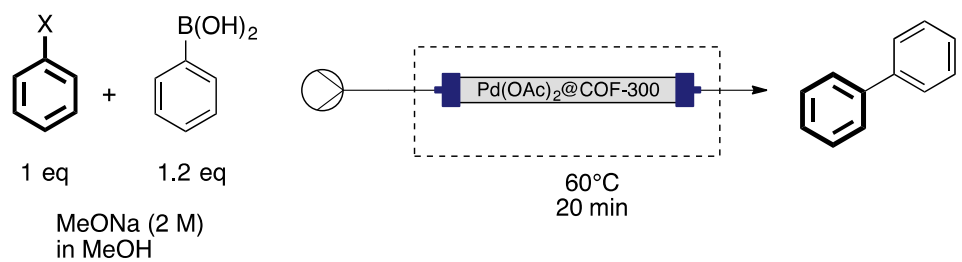

Scheme 23. Suzuki-Miyaura cross coupling in a flow system using $\operatorname{Pd}(\mathrm{OAc})_{2} @ \mathrm{COF}-300$.

An efficient approach was reported for the production of furan-based biaryls [116]. A mixture of aryl halide, boronic acid derivative and TBAF in methanol $(0.37 \mathrm{M})$ was injected through an $\mathrm{X}$-cube fitted with a FC1032 catalyst at flow rate of $0.5 \mathrm{~mL} \mathrm{~min}^{-1}$ at $120^{\circ} \mathrm{C}$ for $2 \mathrm{~h}$ (Scheme 24).
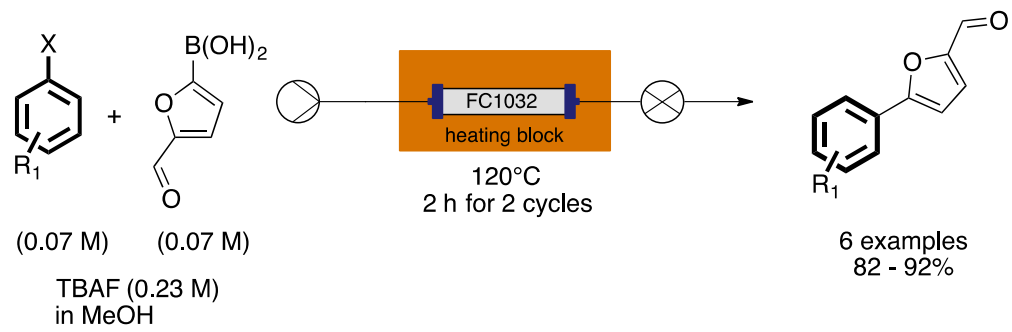

Scheme 24. Suzuki-Miyaura cross coupling in a flow system X-Cube using FC1032 catalyst.

Over to catalyst cycles, the furan derivatives were obtained in good yields (82-92\%) using FC1032 catalyst as $t$-butyl based palladium polymer (Figure 7) [116].

The same process was developed after substitution of FC1032 catalyst by $\mathrm{PdCl}_{2}\left(\mathrm{PPh}_{3}\right)_{2} \mathrm{DVB}$ catalyst at flow rate of $0.3 \mathrm{~mL} \mathrm{~min}{ }^{-1}$ at $120{ }^{\circ} \mathrm{C}$ for $3 \mathrm{~h}$. It is well known that $\mathrm{PdCl}_{2}\left(\mathrm{PPh}_{3}\right)_{2} \mathrm{DVB}$ catalyst is a more efficient catalyst than FC1032 catalyst. In this regard; starting with the deactivated aryl bromides or aryl chlorides in the presence of $\mathrm{PdCl}_{2}\left(\mathrm{PPh}_{3}\right)_{2} \mathrm{DVB}$ catalyst afforded the target furan-based biaryls in 83-92\% yields (Figure 8) [116]. 

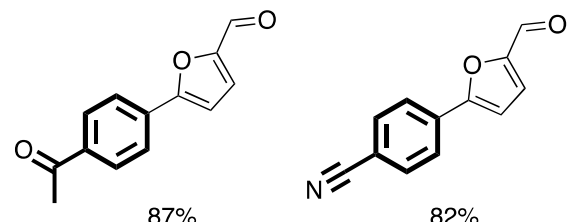<smiles>Cc1ccc(-c2ccc(C=O)o2)cc1</smiles><smiles>CN(C)c1cccc2c(NS(=O)(=O)c3ccc(-c4ccc(C=O)o4)cc3)cccc12</smiles><smiles>COc1ccc(NC(=O)c2ccc(-c3ccc(C=O)o3)cc2)c(OC)c1</smiles>

Figure 7. Substrate scope of continuous flow Suzuki-Miyaura cross-coupling sequence using FC1032 catalyst.<smiles>CN(C)c1cccc(-c2ccc(C=O)o2)c1</smiles>

$87 \%$<smiles>CN(C)c1ccc(-c2ccc(C=O)o2)cc1</smiles>

$87 \%$<smiles>COc1ccc(-c2ccc(C=O)o2)cc1</smiles>

$92 \%$<smiles>O=Cc1ccc(-c2ccc3[nH]ccc3c2)o1</smiles>

$83 \%$<smiles>O=Cc1ccc(-c2ccc(C(=O)c3ccccc3)cc2)o1</smiles>

$87 \%$<smiles>O=Cc1cccc(-c2ccc(C=O)o2)c1</smiles>

$85 \%$

Figure 8. Substrate scope of continuous flow Suzuki-Miyaura cross-coupling sequence using $\mathrm{PdCl}_{2}\left(\mathrm{PPh}_{3}\right)_{2} \mathrm{DVB}$ catalyst.

\section{Concluding Remarks}

The main focus of this review has been the observance of the continuous flow chemistry and Suzuki-Miyaura cross-coupling reactions. Homogeneous Suzuki-Miyaura cross-coupling reactions have been reported in two different elegant and modular strategies: (i) lithiation/ borylation/homogeneous Suzuki-Miyaura sequence using a three-step triphasic flow system; and (ii) diazotization/iododediazotization/homogeneous Suzuki-Miyaura sequence using a three-step triphasic flow system. More examples have been reported in heterogeneous Suzuki-Miyaura cross-coupling reactions. Some groups used $\mathrm{Pd}(0)$ as the active catalyst and some groups preferred to start with $\mathrm{Pd}(\mathrm{II})$ as precursor of $\mathrm{Pd}(0)$. Whatever the type of catalyst, homogeneous, heterogeneous, $\mathrm{Pd}(\mathrm{II})$ or $\mathrm{Pd}(0)$, the residence times were less than one hour and the Pd loading were low compared with the conversion, yield and selectivity. As mentioned by Kappe, "palladium which is leached from the support is most likely responsible for the catalysis, thus suggesting a (quasi)homogeneous mechanism". In this 
regard, homogeneous metal catalyst/ligand system should probably be more efficient if the recycling of the catalyst could be improved.

Depending on the parameters used (concentrations, temperature, pressure, etc.), the lifetime of all the elements of the process, pumps, pipes and reactors, is longer or shorter. To date, no realistic study has been published on this aspect. Varying the nature of the materials, and the designs of the reactor with the microfluidic system, the possibilities to work in high concentrations are new avenues to explore in the future. Chemists and chemical engineers have the means to pave the way to a more widespread implementation of continuous flow strategies for the production of industrially relevant products in the future. Importantly, we hope that these demonstrated advantages of combining Suzuki-Miyaura cross-coupling reaction and flow processes can stimulate further advances in the field from the younger generations for the benefit of the chemical industry in the future.

Author Contributions: S.B. and F.D. analyzed the data; C.L. and V.S.P. wrote the paper.

Conflicts of Interest: The authors declare no conflict of interest.

\section{References}

1. Yin, L.; Liebscher, J. Carbon-carbon coupling reactions catalyzed by heterogeneous palladium catalysts. Chem. Rev. 2007, 107, 133-173. [CrossRef] [PubMed]

2. Barnard, C. Palladium-catalyzed C-C coupling: Then and now. Platin. Met. Rev. 2008, 52, 38-45. [CrossRef]

3. Johansson Seechurn, C.C.C.; Kitching, M.O.; Colacot, T.J.; Sniekus, V. Palladium-catalyzed cross-coupling: A historical contextual perspective to the 2010 Nobel Prize. Angew. Chem. Int. Ed. 2012, 51, 5062-5085. [CrossRef] [PubMed]

4. Agrofoglio, L.A.; Gillaizeau, I.; Saito, Y. Palladium-assisted routes to nucleosides. Chem. Rev. 2003, 103, 1875-1916. [CrossRef] [PubMed]

5. Polshettiwar, V.; Len, C.; Fihri, A. Silica-supported palladium: Sustainable catalysts for cross-coupling reactions. Coord. Chem. Rev. 2009, 253, 2599-2626. [CrossRef]

6. Heck, R.F. Acylation, methylation, and carboxyalkylation of olefins by group VIII metal derivatives. J. Am. Chem. Soc. 1968, 90, 5518-5526. [CrossRef]

7. Mizoroki, T.; Mori, K.; Ozaki, A. Arylation of olefin with aryl iodide catalyzed by palladium. Bull. Chem. Soc. Jpn. 1971, 44, 581. [CrossRef]

8. Heck, R.F.; Nolley, J.P. Palladium-catalyzed vinylic hydrogen substitution reactions with aryls benzyl, and styryl halides. J. Org. Chem. 1972, 37, 2320-2322. [CrossRef]

9. Heck, R.F. Palladium-catalyzed reactions of organic halides with olefins. Acc. Chem. Res. 1979, 12, 146-151. [CrossRef]

10. Dieck, H.A.; Heck, R.F. Organophosphinepalladium complexes as catalysts for vinylic hydrogen substitution reactions. J. Am. Chem. Soc. 1974, 96, 1133-1136. [CrossRef]

11. Beletskaya, I.P.; Cheprakov, A.V. The Heck reaction as a sharpening stone of palladium catalysis. Chem. Rev. 2000, 100, 3009-3066. [CrossRef] [PubMed]

12. Miyaura, N.; Yamada, K.; Suzuki, A. A new stereospecific cross-coupling by the palladium-catalyzed reaction of 1-alkenylboranes with 1-alkenyl or 1-alkynyl halides. Tetrahedron Lett. 1979, 20, 3437-3440. [CrossRef]

13. Miyaura, N.; Yanagi, T.; Suzuki, A. The palladium-catalyzed cross-coupling reaction of phenylboronic acid with haloarenes in the presence of bases. Synt. Commun. 1981, 11, 513-519. [CrossRef]

14. Miyaura, N.; Suzuki, A. Palladium-catalyzed cross-coupling reactions of organoboron compounds. Chem. Rev. 1995, 95, 2457-2483. [CrossRef]

15. Suzuki, A. Recent advances in the cross-coupling reactions of organoboron derivatives with organic electrophiles, 1995-1998. J. Organomet. Chem. 1999, 576, 147-168. [CrossRef]

16. Suzuki, A. Cross-coupling reactions of organoboranes: An easy way to construct $\mathrm{C}-\mathrm{C}$ bonds. Angew. Chem. Int. Ed. 2011, 50, 6722-6764. [CrossRef] [PubMed]

17. Sonogashira, K.; Tohda, Y.; Hagihara, N. A convenient synthesis of acetylenes: Catalytic substitutions of acetylenic hydrogen with bromoalkenes, iodoarenes and brompyridines. Tetrahedron Lett. 1975, 16, 4467-4470. [CrossRef] 
18. Paterson, I.; Davies, R.D.; Marquez, R. Total synthesis of the Callipeltoside aglycon. Angew. Chem. Int. Ed. 2001, 40, 603-607. [CrossRef]

19. Toyota, M.; Komori, C.; Ihara, M. A concise formal total synthesis of Mappicine and Nothapodytine B via an intramolecular hetero Diels-Alder reaction. J. Org. Chem. 2000, 65, 7110-7113. [CrossRef] [PubMed]

20. Nicolaou, K.C.; Dai, W.M. Chemistry and biology of the enediyne anticancer antibiotics. Angew. Chem. Int. Ed. 1991, 30, 1387-1416. [CrossRef]

21. Wu, R.; Schumm, J.S.; Pearson, D.L.; Tour, J.M. Convergent synthetic routes to orthogonally fused conjugated oligomers directed toward molecular scale electronic device applications. J. Org. Chem. 1996, 61, 6906-6921. [CrossRef] [PubMed]

22. Milstein, D.; Stille, J.K. A general, selective, and facile method for ketone synthesis from acid chlorides and organotin compounds catalyzed by palladium. J. Am. Chem. Soc. 1978, 100, 3636-3638. [CrossRef]

23. Milstein, D.; Stille, J.K. Palladium-catalyzed coupling of tetraorganotin compounds with aryl and benzyl halides. Synthetic utility and mechanism. J. Am. Chem. Soc. 1979, 101, 4992-4998. [CrossRef]

24. Stille, J.K. The palladium-catalyzed cross-coupling reactions of organotin reagents with organic electrophiles. Angew. Chem. Int. Ed. 1986, 25, 508-524. [CrossRef]

25. Espinet, P.; Echavarren, A.M. The mechanisms of Stille reaction. Angew. Chem. Ed. Int. 2004, 43, 4704-4734.

26. Hiyama, T.; Hatanaka, Y. Palladium-catalyzed cross-coupling reaction of organometalloids through activation with fluoride ion. Pure Appl. Chem. 1994, 66, 1471-1478. [CrossRef]

27. King, A.O.; Okukado, N.; Negishi, E. Highly general stereo-, regio-, and chemo-selective synthesis of terminal and internal conjugated enynes by the Pd-catalyzed reaction of alkynylzinc reagents with alkenyl halides. J. Chem. Soc. Chem. Commun. 1977, 683-684. [CrossRef]

28. Tamao, K.; Sumitani, K.; Kumada, M. Selective carbon-carbon bond formation by cross-coupling of Grignard reagents with organic halides. Catalysis by nickel-phosphine complexes. J. Am. Chem. Soc. 1972, 94, 4374-4376. [CrossRef]

29. Yamamura, M.; Moritani, I.; Murahashi, S.I. The reaction of $\sigma$-vinylpalladium complexes with alkyllithiums. Stereospecific syntheses of olefins from vinyl halides and alkyllithiums. J. Organomet. Chem. 1975, 91, C39-C42. [CrossRef]

30. Hartwig, J.F. Handbook of Organopalladium Chemistry in Organic Synthesis; Negishi, E., Ed.; Wiley-Interscience: New York, NY, USA, 2003; p. 1051.

31. Jiang, L.; Buchwald, S.L. Metal-Catalyzed Cross-Coupling Reactions; Meijere, A., Diederich, F., Eds.; Wiley-VCH: Weinheim, Germany, 2004; p. 699.

32. Polshettiwar, V.; Decottignies, A.; Len, C.; Fihri, A. Suzuki-Miyaura cross-coupling reactions in aqueous media: Green and sustainable syntheses of biaryls. ChemSusChem 2010, 5, 502-522. [CrossRef] [PubMed]

33. Fihri, A.; Luart, D.; Len, C.; Solhi, A.; Chevrin, C.; Polshettiwar, V. Suzuki-Miyaura cross-coupling reactions with low catalyst loading: A green and sustainable protocol in pure water. Dalton Trans. 2011, 40, 3116-3121. [CrossRef] [PubMed]

34. Sartori, G.; Enderlin, G.; Herve, G.; Len, C. Highly effective synthesis of C-5-substituted 2'-deoxyuridine using Suzuki-Miyaura cross-coupling in water. Synthesis 2012, 44,767-772. [CrossRef]

35. Hassine, A.; Sebti, S.; Solhy, A.; Zahouily, M.; Len, C.; Hedhili, M.N.; Fihri, A. Palladium supported on natural phosphate: Catalyst for Suzuki coupling reactions in water. Appl. Catal. A Gen. 2013, 450, 13-18. [CrossRef]

36. Sartori, G.; Enderlin, G.; Herve, G.; Len, C. New efficient approach for the ligand-free Suzuki-Miyaura reaction of 5-iodo-2'-deoxyuridine in water. Synthesis 2013, 45, 330-333. [CrossRef]

37. Decottignies, A.; Fihri, A.; Azemar, G.; Djedaini-Pilard, F.; Len, C. Ligandless Suzuki-Miyaura reaction in neat water with or without native $\beta$-cyclodextrin as additive. Catal. Commun. 2013, 32, 101-107. [CrossRef]

38. Gallagher-Duval, S.; Herve, G.; Sartori, G.; Enderlin, G.; Len, C. Improved microwave-assisted ligand free Suzuki-Miyaura cross-coupling of 5-iodo-2'-deoxyuridine in pure water. New J. Chem. 2013, 37, $1989-1995$. [CrossRef]

39. Enderlin, G.; Sartori, G.; Herve, G.; Len, C. Synthesis of 6-aryluridines via Suzuki-Miyaura cross-coupling reaction at room temperature under aerobic ligand-free conditions in neat water. Tetrahedron Lett. 2013, 54, 3374-3377. [CrossRef]

40. Herve, G.; Sartori, G.; Enderlin, G.; Mackenzie, G.; Len, C. Palladium-catalyzed Suzuki reaction in aqueous solvents applied to unprotected nucleosides and nucleotides. RSC Adv. 2014, 4, 18558-18594. [CrossRef] 
41. Herve, G.; Len, C. First ligand-free, microwave-assisted, Heck cross-coupling reaction in pure water on a nucleoside-Application to the synthesis of antiviral BVDU. RSC Adv. 2014, 4, 46926-46929. [CrossRef]

42. Lussier, T.; Herve, G.; Enderlin, G.; Len, C. Original access to 5-aryluracils from 5-iodo-2'-deoxyuridine via a microwave-assisted Suzuki-Miyaura cross-coupling/deglycosylation sequence in pure water. RSC Adv. 2014, 4, 46218-46223. [CrossRef]

43. Hassine, A.; Bouhrara, M.; Sebti, S.; Solhy, A.; Luart, D.; Len, C.; Fihri, A. Natural phosphate-supported palladium: A highly efficient and recyclable catalyst for the Suzuki-Miyaura coupling under microwave irradiation. Curr. Org. Chem. 2014, 18, 3141-3148. [CrossRef]

44. Haswell, S.J.; Watts, P. Green chemistry: Synthesis in micro reactors. Green Chem. 2003, 5, 240-249. [CrossRef]

45. Frost, C.G.; Mutton, L. Heterogeneous catalytic syntheis using microreactor technology. Green Chem. 2010, 12, 1687-1703. [CrossRef]

46. Wiles, C.; Watts, P. Continuous flow reactors: A perspective. Green Chem. 2012, 14, 38-54. [CrossRef]

47. Newman, S.G.; Jensen, K.F. The role of flow in green chemistry and engineering. Green Chem. 2013, 15, 1456-1472. [CrossRef]

48. Wiles, C.; Watts, P. Continuous process technology: A tool for sustainable production. Green Chem. 2014, 16, 55-62. [CrossRef]

49. Vaccaro, L.; Lanari, D.; Marrochi, A.; Strappaveccia, G. Flow approaches towards sustainability. Green Chem. 2014, 16, 3680-3704. [CrossRef]

50. Falb, S.; Tomaiuolo, G.; Perazzo, A.; Hodgson, P.; Yaseneva, P.; Zakrzewski, J.; Guido, S.; Lapkin, A.; Woodward, R.; Meadows, R.E. A continuous process for Buchwald-Hartwig amination at micro-, lab-, and mesoscale using a novel reactor concept. Org. Process Res. Dev. 2016, 20, 558-565.

51. Gemoets, H.P.L.; Hessel, V.; Noel, T. Aerobic C-H olefination of indoles via a cross-dehydrogenative coupling in continuous flow. Org. Lett. 2014, 16, 5800-5803. [CrossRef] [PubMed]

52. Reynolds, W.R.; Plucinski, P.; Frost, C.G. Robust and reusable supported palladium catalysts for cross-coupling reactions in flow. Catal. Sci. Technol. 2014, 4, 948-954. [CrossRef]

53. Bourne, S.L.; O’Brien, M.; Kasinathan, S.; Koos, P.; Tolstoy, P.; Hu, D.X.; Bates, R.W.; Martin, B.; Schenkel, B.; Ley, S.V. Flow chemistry syntheses of styrenes, unsymmetrical stilbenes and branched aldehydes. ChemCatChem 2013, 5, 159-172. [CrossRef]

54. Peeva, L.; da Silva Burgal, J.; Vartak, S.; Livingston, A.G. Experimental strategies for increasing the catalyst turnover number in a continuous Heck coupling reaction. J. Catal. 2013, 306, 190-201. [CrossRef]

55. Sharma, S.; Basavaraju, K.C.; Singh, A.K.; Kim, D.P. Continuous recycling of homogeneous Pd/cu catalysts for cross-coupling reactions. Org. Lett. 2014, 16, 3974-3977. [CrossRef] [PubMed]

56. Peeva, L.; Arbour, J.; Livingston, A. On the potential of organic solvent nanofiltration in continuous Heck coupling reactions. Org. Process. Res. Dev. 2013, 17, 967-975. [CrossRef]

57. Domier, R.C.; Moore, J.N.; Shaughnessy, K.H.; Hartman, R.L. Kinetic analysis of aqueous-phase Pd-catalyzed, $\mathrm{Cu}$-free direct arylation of terminal alkynes using a hydrophilic ligand. Org. Process. Res. Dev. 2013, 17, 1262-1271. [CrossRef]

58. Tukacs, J.M.; Jones, R.V.; Darvas, F.; Dibo, G.; Lezsak, G.; Mika, L.T. Synthesis of $\gamma$-valerolactone using a continuous flow reactor. RSC Adv. 2013, 3, 16283-16287. [CrossRef]

59. Yang, G.R.; Bae, G.; Choe, J.; Lee, S.; Song, K.H. Silica-supported palladium-catalyzed Hiyama cross-coupling reactions using continuous flow system. Bull. Korean Chem. Soc. 2010, 31, 250-252. [CrossRef]

60. Phan, N.T.S.; Brown, D.H.; Styring, P. A facile method for catalyst immobilization on silica: Nickel-catalyzed Kumada reactions in mini-continuous flow and batch reactors. Green Chem. 2004, 6, 526-532. [CrossRef]

61. Alonso, N.; Zane Miller, L.; Munoz, J.D.M.; Alcazar, J.; Tyler McQuade, D. Continuous synthesis of organozinc halides coupled to Negishi reactions. Adv. Synth. Catal. 2014, 356, 3737-3741. [CrossRef]

62. Tan, L.M.; Sem, Z.Y.; Chong, W.Y.; Liu, X.; Hendra; Kwan, W.L.; Ken Lee, C.L. Continuous flow Sonogashira C-C coupling using a heterogeneous palladium-copper dual reactor. Org. Lett. 2013, 15, 65-67. [CrossRef] [PubMed]

63. Zhang, H.H.; Xing, C.H.; Bouobda Tsemo, G.; Hu, Q.S. t-Bu 3 P-coordinated 2-phenylaniline-based palladacycle complex as a precatalyst for the Suzuki cross-coupling polymerization of aryl dibromides with aryldiboronic acids. ACS Macro Lett. 2013, 2, 10-13. [CrossRef] [PubMed]

64. Schulte, N.; Breuning, E.; Spreitzer, H. Method for the Production of Polymers. U.S. Patent 20,080,207,851 A1, 28 December 2004. 
65. Seyler, H.; Jones, D.J.; Holmes, A.B.; Wong, W.W.H. Continuous flow synthesis of conjugated polymers. Chem. Commun. 2012, 48, 1598-1600. [CrossRef] [PubMed]

66. Gao, M.; Subbiah, J.; Geraghty, P.B.; Chen, M.; Purushothaman, B.; Chen, X.; Qin, T.; Vak, D.; Scholes, F.H.; Watkins, S.E.; et al. Development of a high-performance donor-acceptor conjugated polymer: Synergy in materials and device optimization. Chem. Mater. 2016, 28, 3481-3487. [CrossRef]

67. Mitchell, V.D.; Wong, W.W.H. Synthetic Methods for Conjugated Polymer and Carbon Materials; Leclerc, M., Morin, J.-F., Eds.; Wiley-VCH: Weinheim, Germany, 2017; p. 65.

68. Amatore, C.; Jutand, A.; Le Duc, G. Kinetic data for the transmetallation/reductive elimination in palladium-catalyzed Suzuki-Miyaura reactions: Unexpected triple role of hydroxide ions used as base. Chem. Eur. J. 2011, 17, 2492-2503. [CrossRef] [PubMed]

69. Amatore, C.; Jutand, A.; Le Duc, G. Mechanistic origin of antagonist effects of usual anionic bases $\left(\mathrm{OH}^{-}\right.$, $\mathrm{CO}_{3}{ }^{2-}$ ) as modulated by their countercations $\left(\mathrm{Na}^{+}, \mathrm{Cs}^{+}, \mathrm{K}^{+}\right)$in palladium-catalyzed Suzuki-Miyaura reactions. Chem. Eur. J. 2012, 18, 6616-6625. [CrossRef] [PubMed]

70. Carrow, B.P.; Hartwig, J.F. Distinguishing between pathways for transmetalation in Suzuki-Miyara reactions. J. Am. Chem. Soc. 2011, 133, 2116-2119. [CrossRef] [PubMed]

71. Cantillo, D.; Kappe, C.O. Immobilized Transition Metals as Catalysts for Cross-Couplings in Continuous Flow-A Critical Assessment of the Reaction Mechanism and Metal Leaching. ChemCatChem 2014, 6, 3286-3305. [CrossRef]

72. Narayanan, R.; El-Sayed, M.A. Effect of catalysis on the stability of metallic nanoparticles: Suzuki reaction catalyzed by PVP-palladium nanoparticles. J. Am. Chem. Soc. 2003, 125, 8340-8347. [CrossRef] [PubMed]

73. Narayanan, R.; El-Sayed, M.A. Effect of catalytic activity on the metallic nanoparticle size distribution: Electron-transfer reaction between $\mathrm{Fe}(\mathrm{CN})_{6}$ and thiosulfate ions catalyzed by PVP-platinium nanoparticles. J. Phys. Chem. B 2003, 107, 12416-12424. [CrossRef]

74. De Vries, A.H.M.; Mulders, J.; Mommers, J.H.M.; Henderickx, H.J.W.; De Vries, J.G. Homeopathic ligand-free palladium as a catalyst in the Heck reaction. A comparison with a palladacycle. Org. Lett. 2003, 5, 3285-3288. [CrossRef] [PubMed]

75. De Vries, J.G. A unifying mechanism for all high-temperature Heck reactions. The role of palladium colloids and anionic species. Dalton Trans. 2006, 21, 421-429. [CrossRef] [PubMed]

76. Zhao, F.; Bhanage, B.M.; Shirai, M.; Arai, M. Heck reactions of iodobenzene and methyl acrylate with conventional supported palladium catalysts in the presence of organic and/and inorganic bases without ligands. Chem. Eur. J. 2000, 6, 843-848. [CrossRef]

77. Bhanage, B.M.; Shirai, M.; Arai, M. Heterogeneous catalyst system for Heck reaction using supported ethylene glycol phase Pd/TPPTS catalyst with inorganic base. J. Mol. Catal. A 1999, 145, 69-74. [CrossRef]

78. Reetz, M.T.; Westermann, E. Phosphane-free palladium-catalyzed coupling reactions: The decisive role of Pd nanoparticles. Angew. Chem. Int. Ed. 2000, 39, 165-168. [CrossRef]

79. Reetz, M.T.; Helbig, W.; Quasier, S.A.; Stimming, U.; Breuer, N.; Vogel, R. Visualization of surfactants on nanostructured palladium clusters by a combination of STM and high-resolution TEM. Science 1995, 267, 367-369. [CrossRef] [PubMed]

80. Thathagar, M.B.; Ten Elshof, J.E.; Rothenberg, G. Pd nanoclusters in C-C coupling reactions: Proof of leaching. Angew. Chem. Int. Ed. 2006, 45, 2886-2890. [CrossRef] [PubMed]

81. Gaikwad, A.V.; Holuigue, A.; Thathagar, M.B.; Ten Elhof, J.E.; Rothenberg, G. Ion- and atom-leaching mechanisms from palladium nanoparticles in cross-coupling reactions. Chem. Eur. J. 2007, 13, 6908-6913. [CrossRef] [PubMed]

82. Ananikov, V.P.; Beletskaya, I.P. Toward the ideal catalyst: From atomic centers to a "cocktail" of catalysts. Organometallics 2012, 31, 1595-1604. [CrossRef]

83. Kashin, A.S.; Ananikov, V.P. Catalytic C-C and C-heteroatom bond formation reactions: In Situ generated of preformed catalysts? Complicated mechanistic picture behing well-known experimental procedures. J. Org. Chem. 2013, 78, 11117-11125. [CrossRef] [PubMed]

84. Shu, W.; Pellegatti, L.; Oberli, M.A.; Buchwald, S.L. Continuous-flow synthesis of biaryls enabled by multistep solid-handling in a lithiation/borylation/Suzuki-Miyaura cross-coupling sequence. Angew. Chem. Int. Ed. 2011, 50, 10665-10669. [CrossRef] [PubMed]

85. Kabri, Y.; Gellis, A.; Vanelle, P. Synthesis of original 2-substituted 4-arylquinazolines by microwave-irradiated Suzuki-Miyaura cross-coupling reactions. Eur. J. Org. Chem. 2009, 2009, 4059-4066. [CrossRef] 
86. Gill, G.S.; Grobelny, D.W.; Chaplin, J.H.; Flynn, B.L. An efficient synthesis and substitution of 3-aroyl-2-bromobenzo[b]furans. J. Org. Chem. 2008, 73, 1131-1134. [CrossRef] [PubMed]

87. Organ, M.; Calimsiz, S.; Sayah, M.; Hoi, K.; Lough, A. Pd-PEPPSI-IPent: An active, sterically demanding cross-coupling catalyst and its application in the synthesis of tetra-ortho-substituted biaryls. Angew. Chem. Int. Ed. 2009, 48, 2383-2387. [CrossRef] [PubMed]

88. Dang, T.; Chen, Y. One-pot oxidation and bromination of 3,4-diaryl-2,5-dihydrothiophenes using $\mathrm{Br}_{2}$ : Synthesis and application of 3,4-diaryl-2,5-dibromothiophenes. J. Org. Chem. 2007, 72, 6901-6904. [CrossRef] [PubMed]

89. Maeda, H.; Haketa, Y.; Nakanishi, T. Aryl-substituted C3-bridged oligopyrroles as anion receptors for formation of supramolecular organogels. J. Am. Chem. Soc. 2007, 129, 13661-13674. [CrossRef] [PubMed]

90. James, C.A.; Coelho, A.L.; Gevaert, M.; Forgione, P.; Snieckus, V. Combined directed ortho and remote metalation-Suzuki cross-cooupling strategies. Efficient synthesis of heteroaryl-fused benzopyrannones from biaryl O-carbamates. J. Org. Chem. 2009, 74, 4094-4103. [CrossRef] [PubMed]

91. Giodiano, C.; Coppi, L.; Minisci, F. Process for the Preparation of 5-(2,4-difluorophenyl)-salicylic Acid. U.S. Patent 5,312,975, 17 May 1994.

92. Hannah, J.; Ruyle, W.V.; Jones, H.; Matzuk, A.R.; Kelly, K.W.; Witzel, B.E.; Holtz, W.J.; Houser, R.A.; Shen, T.Y.; Sarett, L.H. Novel analgesic-antiinflammatory salicylates. J. Med. Chem. 1978, 21, 1093-1100. [CrossRef] [PubMed]

93. Reizman, B.J.; Wang, Y.M.; Buchwald, S.L.; Jensen, K.F. Suzuki-Miyaura cross-coupling optimization enabled by automated feedback. React. Chem. Eng. 2016, 1, 658-666. [CrossRef] [PubMed]

94. Teci, M.; Tilley, M.; McGuire, M.A.; Organ, M.G. Using anilines as masked cross-coupling partners: Design of a telescoped three-step flow diazotization, iododediazotization, cross-coupling process. Chem. Eur. J. 2016, 22, 1-10. [CrossRef] [PubMed]

95. Ormerod, D.; Lefevre, N.; Dorbec, M.; Eyskens, I.; Vloemans, P.; Duyssens, K.; Diez de la Torre, V.; Kaval, N.; Merkul, E.; Sergeyev, S.; et al. Potential of homogeneous Pd catalyst separation by ceramic membranes. Application to downstream and continuous flow processes. Org. Process Res. Dev. 2016, 20, 911-920. [CrossRef]

96. Cole, K.P.; Campbell, B.M.; Forst, M.B.; McClary Groh, J.; Hess, M.; Johnson, M.D.; Miller, R.D.; Mitchell, D.; Polster, C.S.; Reizman, B.J.; et al. An automated intermittent flow approach to continuous Suzuki coupling. Org. Process Res. Dev. 2016, 20, 820-830. [CrossRef]

97. Hattori, T.; Tsubone, A.; Sawama, Y.; Monguchi, Y.; Sajiki, H. Palladium on carbon-catalyzed Suzuki-Miyaura coupling reaction using an efficient and continuous flow system. Catalysts 2015, 5, 18-25. [CrossRef]

98. Brinkley, K.W.; Burkholder, M.; Siamaki, A.R.; Belecki, K.; Gupton, B.F. The continuous synthesis and application of graphene supported palladium nanoparticles: A highly effective catalyst for Suzuki-Miyaura cross-coupling reactions. Green Process Synth. 2015, 4, 241-246. [CrossRef]

99. Bolton, K.F.; Canty, A.J.; Deverell, J.A.; Guijt, R.M.; Hilder, E.F.; Rodemann, T.; Smith, J.A. Macroporous monolith supports for continuous flow capillary microreactors. Tetrahedron Lett. 2006, 47, 9321-9324. [CrossRef]

100. Nagaki, A.; Hirose, K.; Moriwaki, Y.; Mitamura, K.; Matsukawa, K.; Ishizuka, N.; Yoshida, J. Integration of borylation of aryllithiums and Suzuki-Miyaura coupling using monolithic Pd catalyst. Catal. Sci. Technol. 2016, 6, 4690-4694. [CrossRef]

101. Shil, A.K.; Guha, N.R.; Sharma, D.; Das, P. A solid supported palladium(0) nano/microparticle catalyzed ultrasound induced continuous flow technique for large scale Suzuki reactions. RSC Adv. 2013, 3, 13671-13676. [CrossRef]

102. Pascanu, V.; Hansen, P.R.; Bermejo-Gomez, A.; Ayats, C.; Platero-Prats, A.E.; Johansson, M.J.; Pericas, M.A.; Martin-Matute, B. Highly functionalized biaryls via Suzuki-Miyaura cross coupling catalyzed by Pd@MOF under batch and continuous flow regimes. ChemSusChem 2015, 8, 123-130. [CrossRef] [PubMed]

103. Ricciardi, R.; Huskens, J.; Verboom, W. Dendrimer-encapsulated Pd nanoparticles as catalysts for C-C cross-couplings in flow microreactors. Org. Biomol. Chem. 2015, 13, 4953-4959. [CrossRef] [PubMed]

104. Ricciardi, R.; Huskens, J.; Holtkamp, M.; Karst, U.; Verboom, W. Dendrimer-encapsulated palladium nanoparticles for continuous-flow Suzuki-Miyaura cross-coupling reactions. ChemCatChem 2015, 7, 936-942. [CrossRef] 
105. Rehm, T.H.; Bogdan, A.; Hofmann, C.; Lob, P.; Shifrina, Z.; Morgan, D.G.; Bronstein, L.M. Proof of concept: Magnetic fixation of dendron-functionalized iron oxide nanoparticles containing Pd nanoparticles for continuous-flow Suzuki coupling reactions. ACS Appl. Mater. Interfaces 2015, 7, 27254-27261. [CrossRef] [PubMed]

106. Seto, H.; Yoneda, T.; Morii, T.; Hoshino, Y.; Miura, Y. Membrane reactor immobilized with palladium-moaded polymer nanogel for continuous-flow Suzuki coupling reaction. AIChE J. 2015, 61, 582-589. [CrossRef]

107. Gu, Y.; Favier, I.; Pradel, C.; Gin, D.L.; Lahitte, J.F.; Noble, R.D.; Gomez, M.; Remigny, J.C. High catalytic efficiency of palladium nanoparticles immobilized in a polymer membrane containing poly(ionic liquid) in Suzuki-Miyaura cross-coupling reaction. J. Membr. Sci. 2015, 492, 331-339. [CrossRef]

108. Dai, Y.; Formo, E.; Li, H.; Xue, J.; Xia, Y. Surface-functionalized electrospun titania nanofibers for the scavenging and recycling of precious metal ions. ChemSusChem 2016, 9, 2912-2916. [CrossRef] [PubMed]

109. Munoz, J.D.M.; Alcazar, J.; de la Hoz, A.; Diaz-Ortiz, A. Cross-coupling in flow using supported catalysts: Mild, clean, efficient and sustainable Suzuki-Miyaura coupling in a single pass. Adv. Synth. Catal. 2012, 354, 3456-3460. [CrossRef]

110. Noel, T.; Kuhn, S.; Musacchio, A.J.; Jensen, K.F.; Buchwald, S.L. Suzuki-Miyaura cross-coupling reactions in flow: Multistep synthesis enabled by a microfluidic extraction. Angew. Chem. Int. Ed. 2011, 50, 5943-5946. [CrossRef] [PubMed]

111. Greco, R.; Goessler, W.; Cantillo, D.; Kappe, C.O. Benchmarking immobilized Di- and Triaryphosphine palladium catalysts for continuous-flow cross-coupling reactions: Efficiency, durability, and metal leaching studies. ACS Catal. 2015, 5, 1303-1312. [CrossRef]

112. Pandarus, V.; Gingras, G.; Beland, F.; Ciriminna, R.; Pagliaro, M. Process intensification of the Suzuki-Miyaura reaction over sol-gel entrapped catalyst SiliaCat DPP-Pd under conditions of continuous flow. Org. Process Res. Dev. 2014, 18, 1550-1555. [CrossRef]

113. Pandarus, V.; Gingras, G.; Beland, F.; Ciriminnia, R.; Pagliaro, M. Fast and clean borylation of aryl halides under flow using sol-gel entrapped SiliaCat DPP-Pd. Org. Process Res. Dev. 2014, 18, 1556-1559. [CrossRef]

114. Pandarus, V.; Ciriminnia, R.; Gingras, G.; Beland, F.; Drobod, M.; Jina, O.; Pagliaro, M. Greening heterogeneous catalysis for fine chemicals. Tetrahedron Lett. 2013, 54, 1129-1132. [CrossRef]

115. Goncalves, R.S.B.; de Oliveira, A.B.V.; Sindra, H.C.; Archanjo, B.S.; Mendoza, M.E.; Carneiro, L.S.A.; Buarque, C.D.; Esteves, P.M. Heterogeneous catalysis by covalent organic frameworks (COF): $\mathrm{Pd}(\mathrm{OAc})_{2} @ \mathrm{COF}-300$ in cross-coupling reactions. ChemCatChem 2016, 8, 743-750. [CrossRef]

116. Trinh, T.N.; Hizartzidis, L.; Lin, A.J.S.; Harman, D.G.; McCluskey, A.; Gordon, C.P. An efficient continuous flow approach to furnish furan-based biaryls. Org. Biomol. Chem. 2014, 12, 9562-9571. [CrossRef] [PubMed] 